هجلة كلية التربية ببورسعيد

خريطة هدرسية للحلقة الأولى هن التعليم الأساسي بمحافظة شمال سيناء

خربلة مدوسية الحلفة الأولمن الثعليم الأسلمي بمحالفلمشملسشيناء

إعداد

دعاءمحمسليملنسلمة

إثرف

أ.م.د /محمدطه ريلن

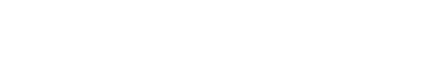

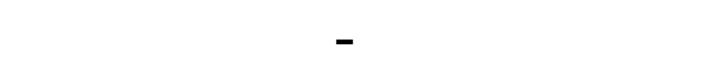

أ. أد / رالثد اصبري الفصبي ألمتاذ أمطط التربية المبري ووكل الللية المشئهن الررلسلت العليا والبحوث

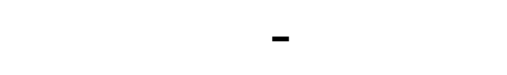

أ.بمد / رفت عمر عزوز

ألستاذ مساعد أمبط النربية

كلية النربية بالمربش -جالمعة قناة اللودس

\{rir

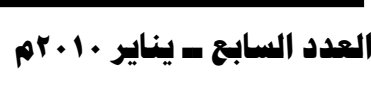


الهقمة:

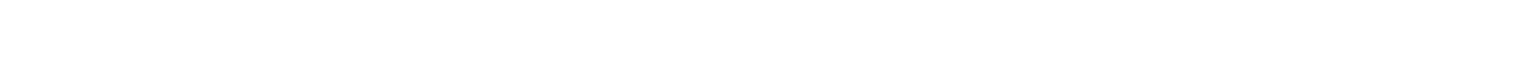

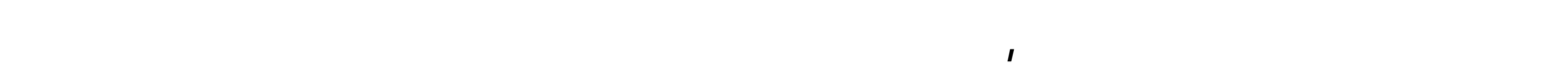

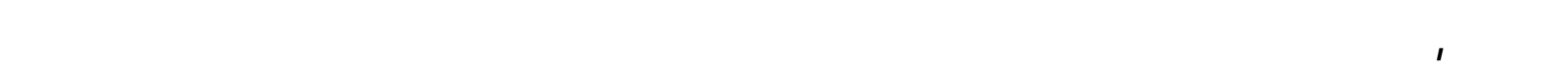

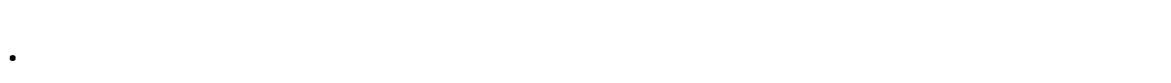

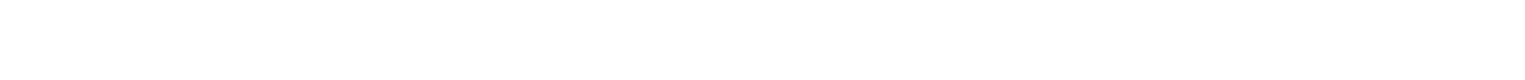

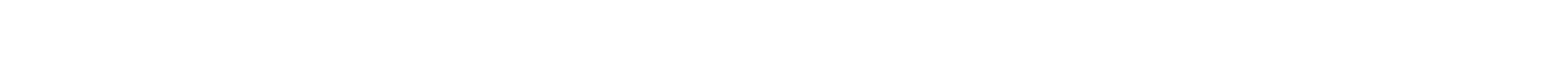

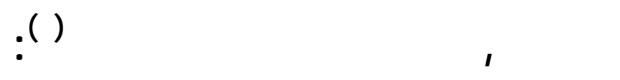

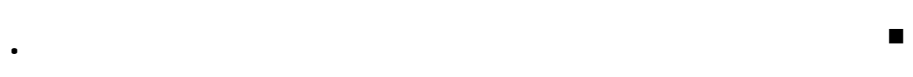

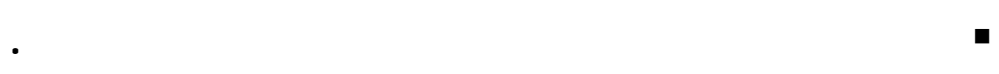

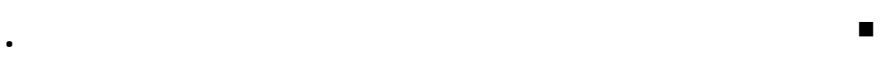

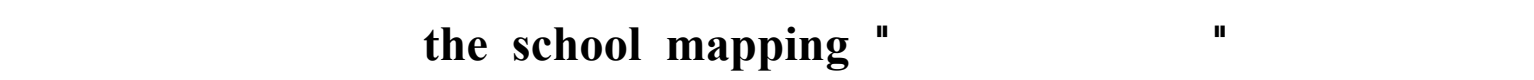

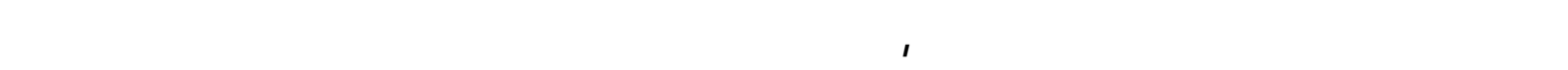

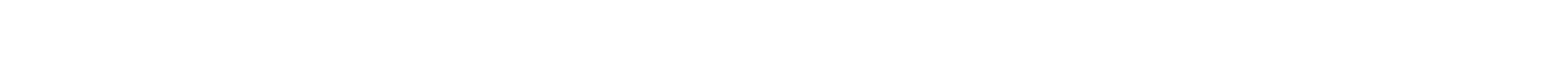

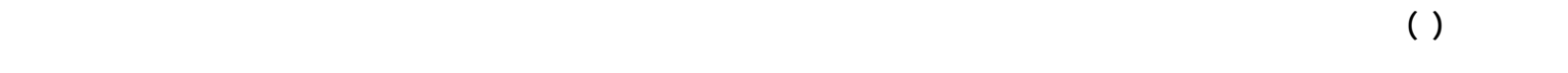

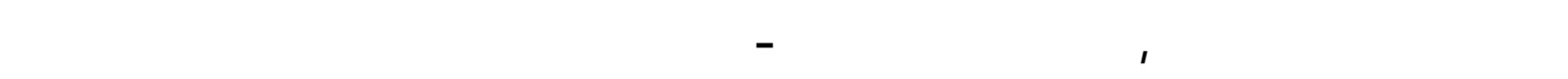

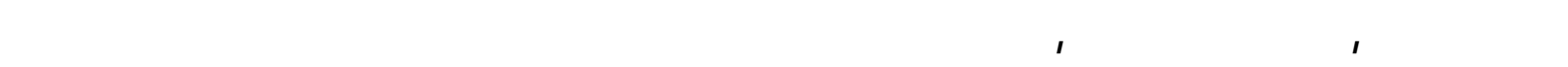
عملية التخاذ الفرارل التربوية, وتهسين قرة ممثلي المجل التريوي على الفيلم بالنظيلا والتفيذ

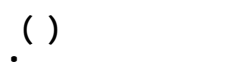

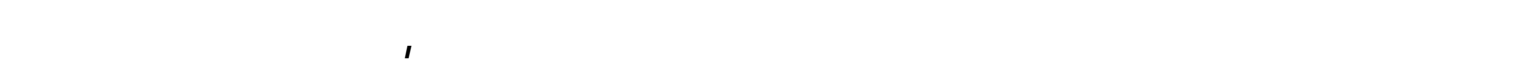

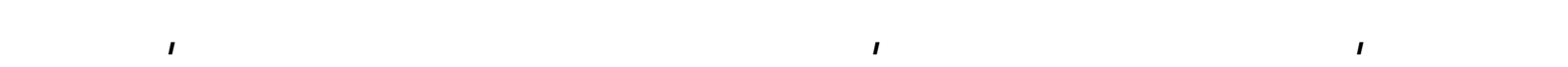

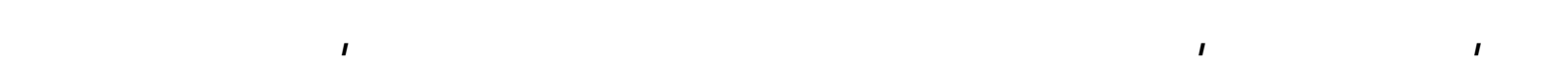

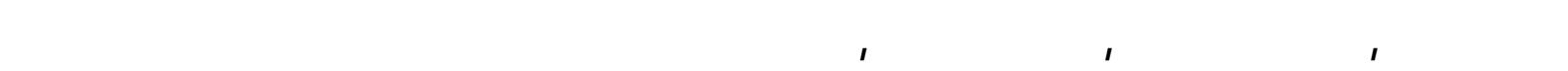
اللسنولت الماضنية.

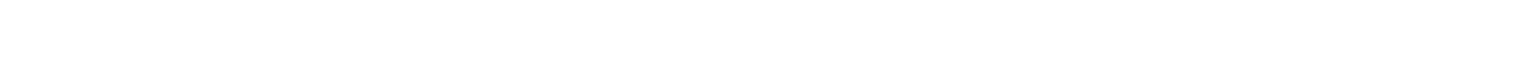

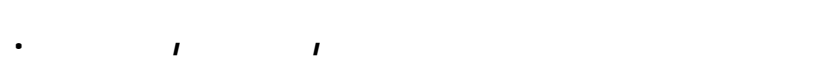




\section{(1) (1) (1)}

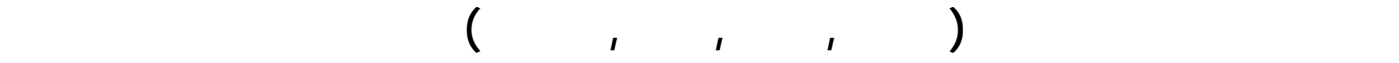

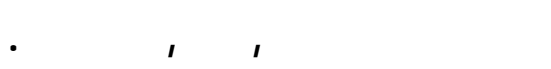

\begin{tabular}{|c|c|c|c|c|c|c|c|c|c|c|c|c|}
\hline \multicolumn{4}{|c|}{ r..t } & \multicolumn{4}{|c|}{1997} & \multicolumn{4}{|c|}{ І9ит } & \multirow[b]{2}{*}{ إركر/ لله } \\
\hline مגקسב" & تلاميذ & همط & مدله & مدעس|" & :لاميذ & فصل & مدلوس & مגקسב" & تلاميذ & فمط & مدلس & \\
\hline ІعVณ & תוז..r & 071 & or & IroA & וعף". & דוع & $\varepsilon$. & rદ१ & OוI ו & r. I & r & لمشش \\
\hline 190 & TVVE & rA. & rA & rren & عтов & rוq & rV & $19 \%$ & rV.r & IVI & rع & لأبند \\
\hline عOA & ^દ११ & m & ع & ודץ & عMNO & 190 & rr & IEA & ल97. & IEA & 7 & بئر البد \\
\hline זדז & ז'ו & rદo & ra & ro9 & or7o & in & 7 & 101 & हт7१ & 10. & rع & فح \\
\hline 119 & זודו & TrE & દદ & 1.9 & १иг & $\mathbf{A V}$ & q & vع & זרצו & 1. & rع & الهيسة \\
\hline r7 & ovv & 09 & 11 & r. & $1 \mathbf{1 A}$ & $1 \varepsilon$ & 0 & 19 & 1.0 & rו & 0 & ] \\
\hline rvin & ع0MТ & 179 & דוז & rદદo & Р११०७ & سוI & IV. & १ัع & rદWvદ & M & דשו & الإ]|] \\
\hline
\end{tabular}

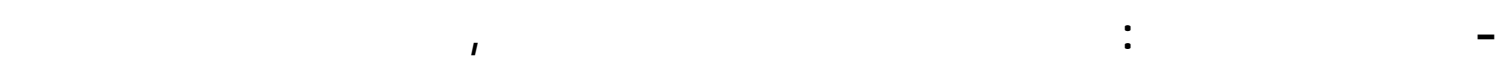

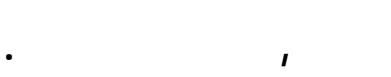

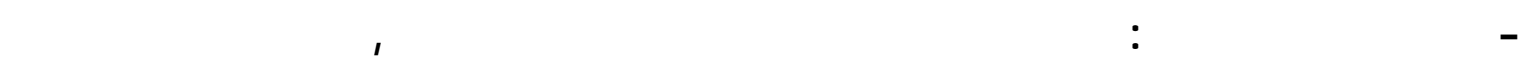

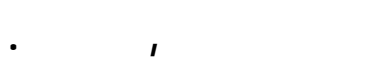

: مشكلة الدرلسة روتساؤلاتها : يمكن حصر مشكلة الررلسة في اللسؤل الرئيس التالل:

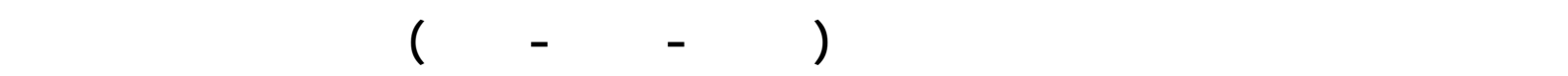

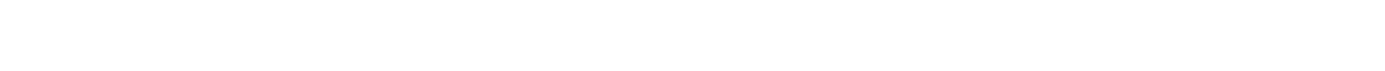

وبفرع من هذا للسؤل الرئيس الأسئلة الفرعية الآتية: ماسفهو الخربلة المدرسية ومقالبلت إعدادها وتفيذها ؟

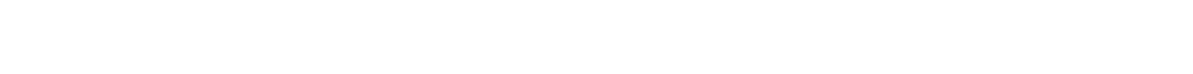

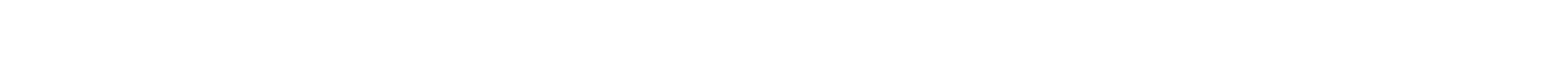

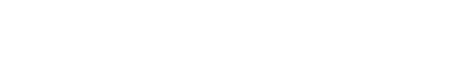


ألهرف الدرلسة :

تسمى الريلسة الحالية لتهق الأهند الآنية:

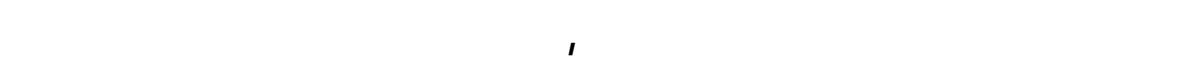

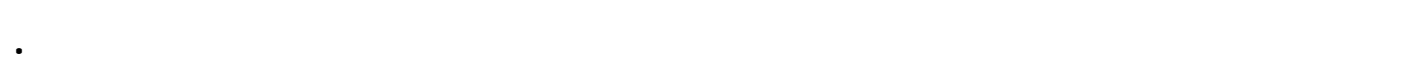

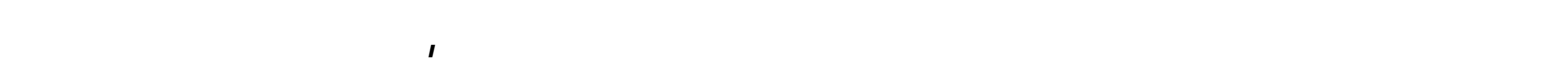
الفرص والنسهيلات النعليمية بين المنلاق. ألهمية الدرلسة:

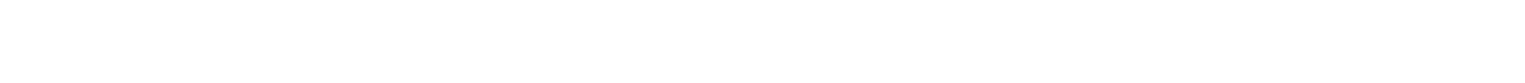

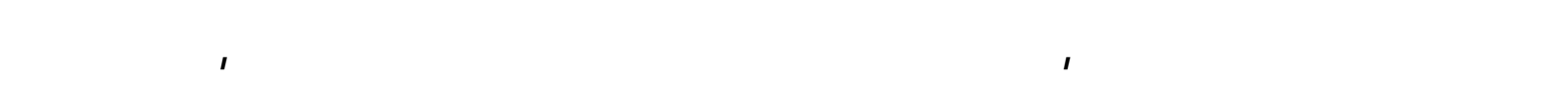

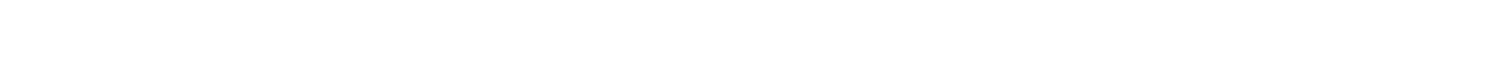
تكؤ الفرص التعليمية. حدود الررلسة: فتصر الررلسة الحالية عل بناء خربلة مدرسية الحلفة الأولمن التعليم الأسلسي لمحانلقشمل عسيناء حق علم IV · مالم.

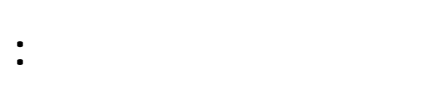

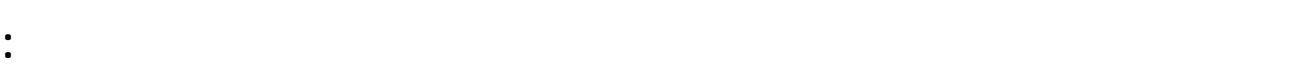

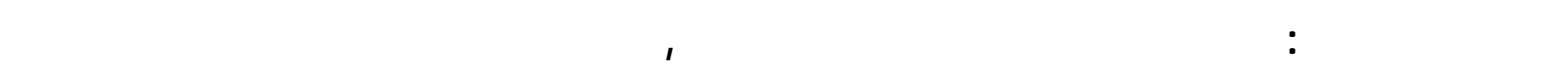

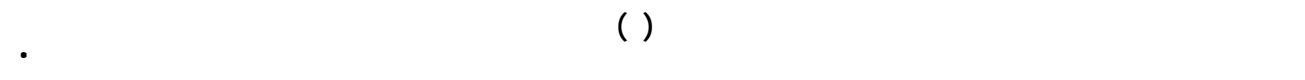

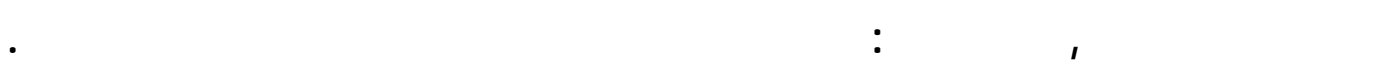

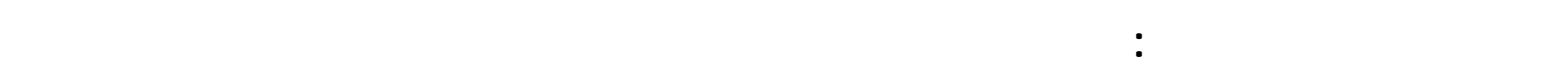

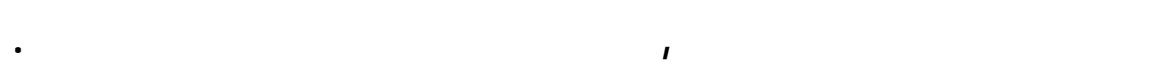
مصطالحلت الدرلسة: : The School Mapping الخربلة المدرسية

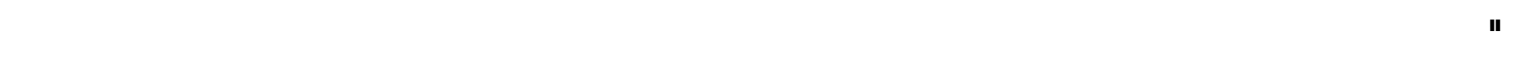

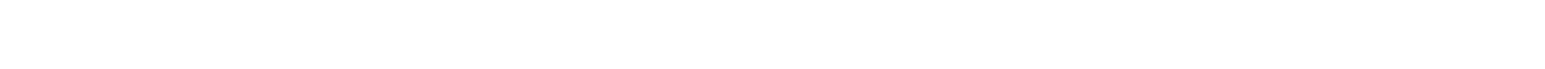
يضمن عدالة توزيع الخملت التعليمية في المجتمع الولدد".

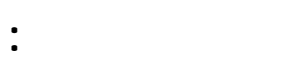




\section{() درلسة أحمد مسن محمد يوسف الجلبر(1997 )(0) .}

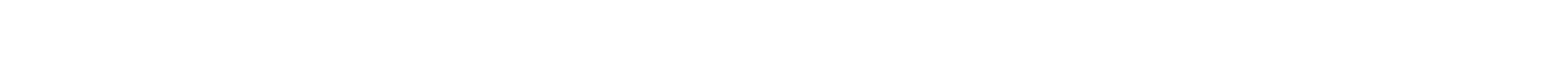
مدى عشرسنولت قالمة, ولستحلت بالمنهج الوصف الجمع البيلنات الملامسة عن وفيع التمليم,

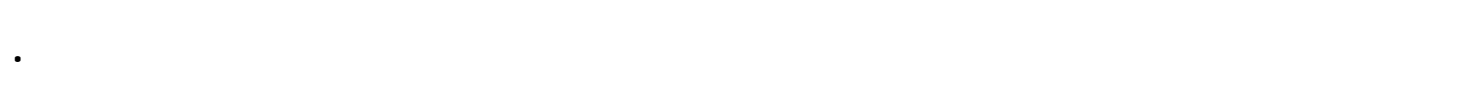
وتوصلت الدرلسة للة نتائج, منها نتائج خامية بتفيذ الخربلة المدرسية لامرحلة البتدائية,

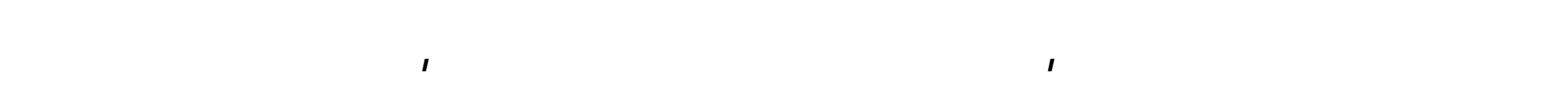

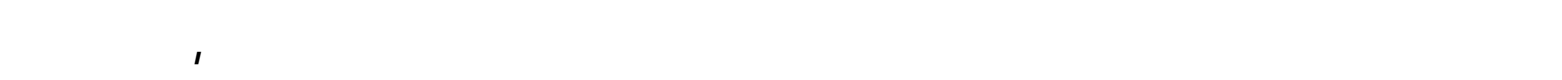

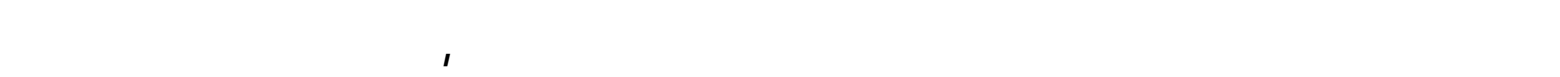

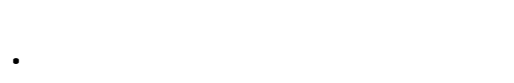

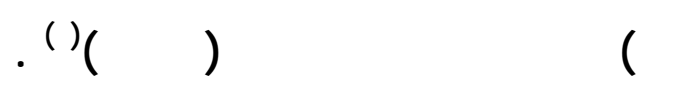

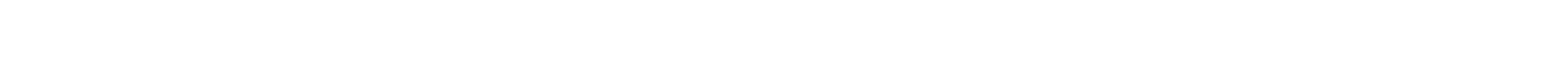
المدسسية, ولستخدت الررلسة المنهج الوصف لرصد الولغ, إلى جلذ ب الإس قلالت الم عسفبلية لاستشره مسقل النعليم الأسلى حت علم ا ـ م وصولا لإعداد تصور الخرطة الفقترح.

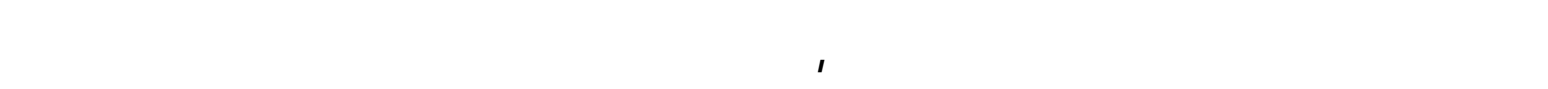

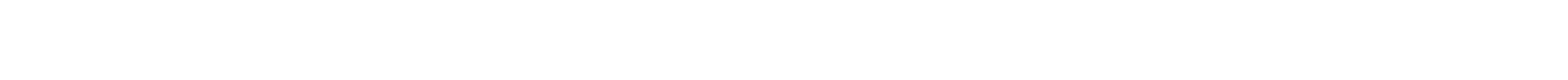

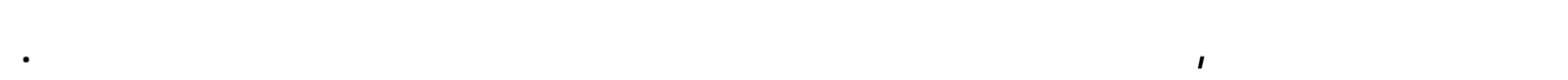
كما أوصت الررلسة بتبني أسلوب الخرولة المدرسية وظلبقه عل مختلف المرلكل النعليمية.

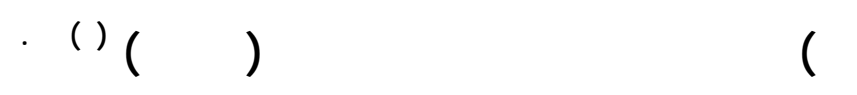

الستهفت الدرلسة علاج المشكلات النحليمية التي يعالف منهامركز المنزلة ومنها عم القدرة

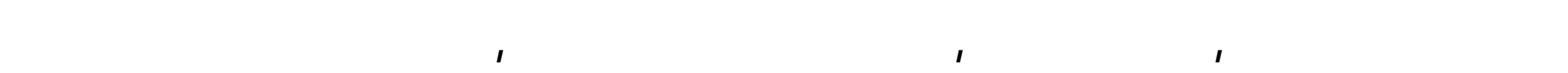

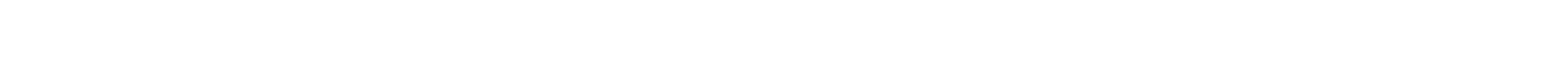

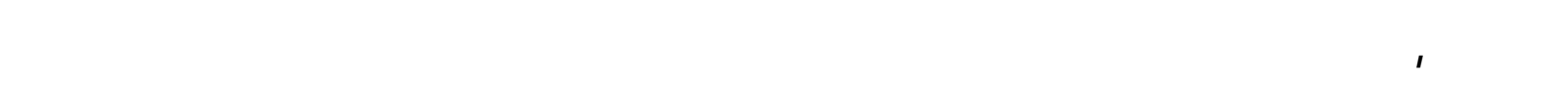

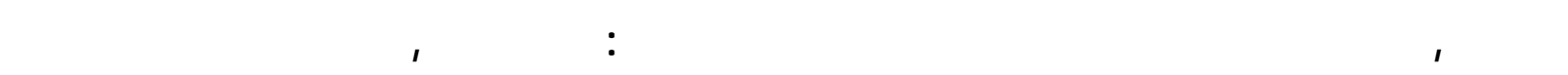
ولإِقةلت. 
وجاعت الرلمسة بعة نتائج منها, عهم التوزيع العلل اللخملت والمخصصلت والفوى الب شربة

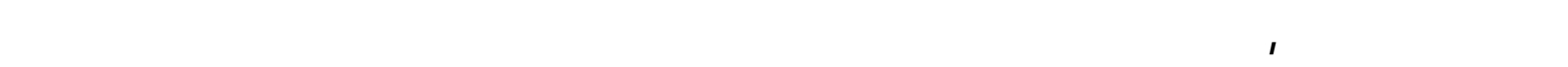
الستيحلب الكالل للثلاميذكماقاهت الرملسة بتحيدمعدلات القبط والاستيحلب فيلى وحقسس كنية وصولاً لوضع نموذج الخرطة المدرسية المنلب,كما لؤوت الررلسة بضرورة النظا يط الجي 2 للأبنية التعليمية وألا تخضو لوفع للارتجالية والعشوائية.

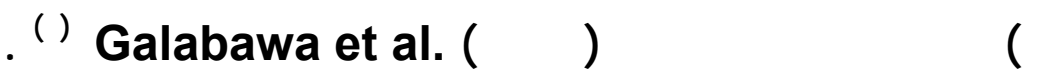

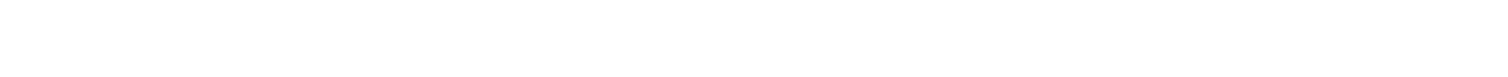

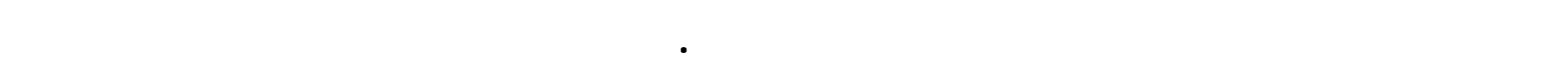

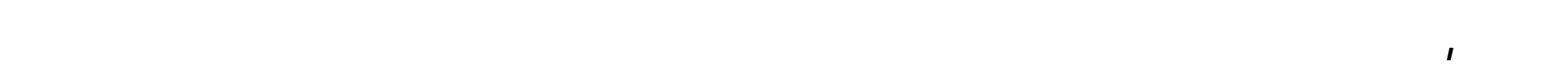
المدرسية وعتدمقلبلاتشخصية ولستبيلنات.

وتوصلت الررلسة لعة نتائج من أهمها, أن أسلوب الخرطة المرسسية قد أثر بشكل ليجلي فم

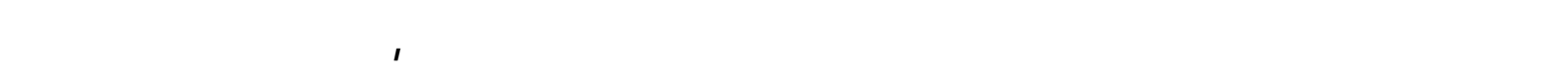
وقلي لل نس ب التسرب, وتهسين عملية الخخ الذ الغرارت التربوبة.

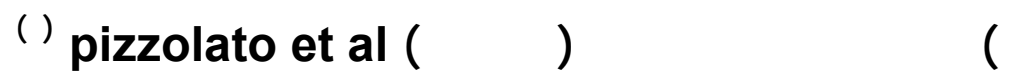

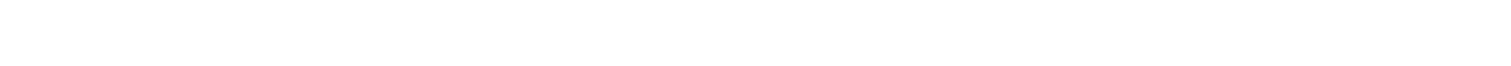

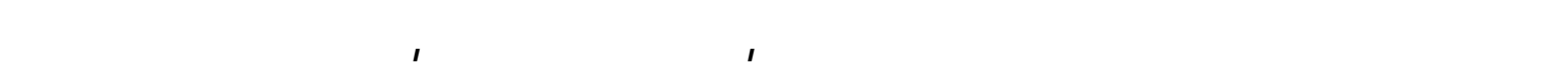

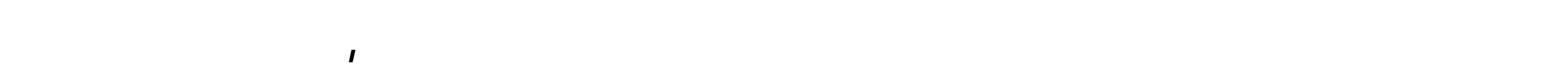

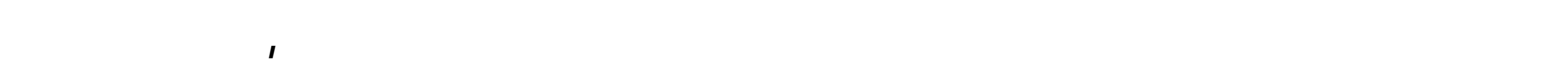
المرلل النهليمية. إلجراءلت الدرلسة:

عسارت الرلسة وفق الظلول الآنية :

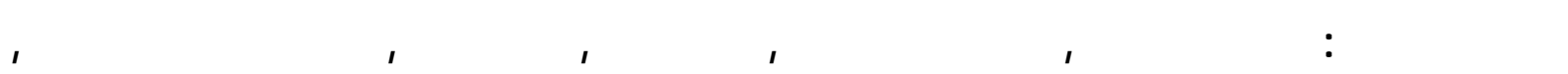
ومصطالحلت الدرلسة والدرلسلت والبحوث اللسابقة, والجراءلت الدرلسة.

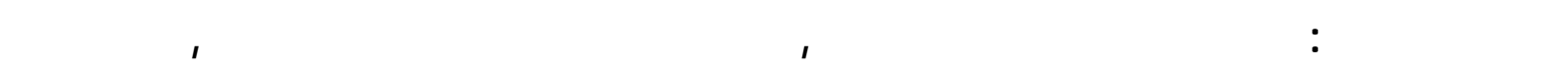
الأخذ بها, أهدافها, وأنميتها, ومقالبلت إعدادها. 
الظلوة الثالثة: تناولت الإلار الهمل للمرلسة, وتتضهن مرللل وضع الخربة المدرس سية, وهم

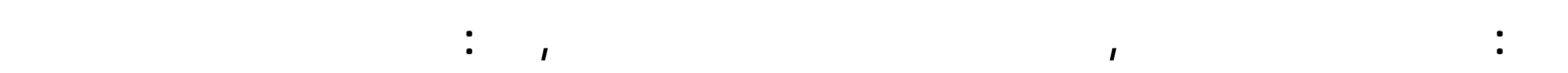

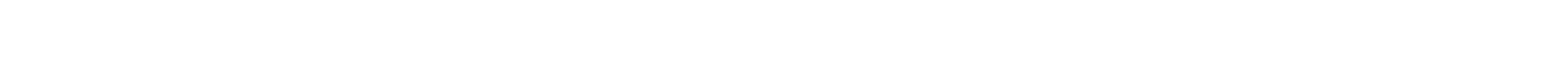
IV -مמ.

\section{أولا: لإلار القاري لالدرلسة}

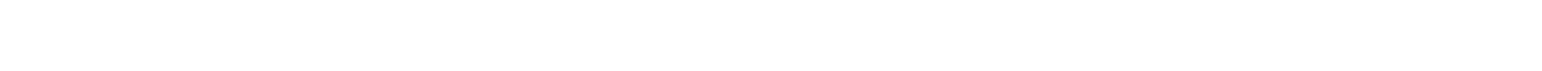

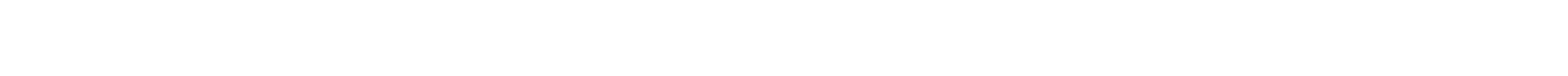

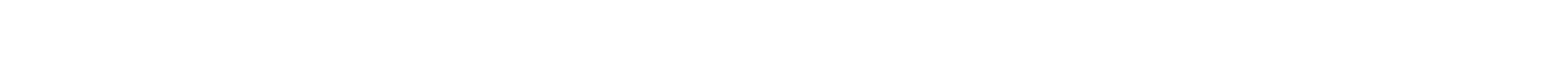
ناحية أخري.

وفيما يأت يقم تنالر الخربة المدرسية من حيث مفهومها, ومبررات الأخذ يها, ألهدلها,

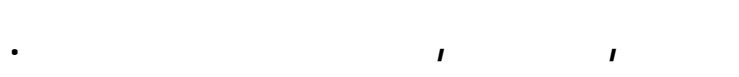

أ - ـفهو الخربة المدرسية :

يمكن تعرف الخرولة المدرسية بأنها "خلة متكاملة النمو النعليي لإفليم أومطاق ة أومدينة

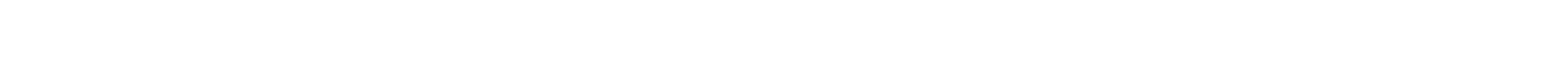
لهابوموفهها بما يفق وأهسل الظطة الثمليمية الموضوعة "(- (1).

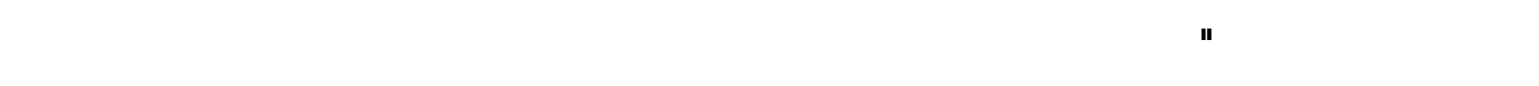

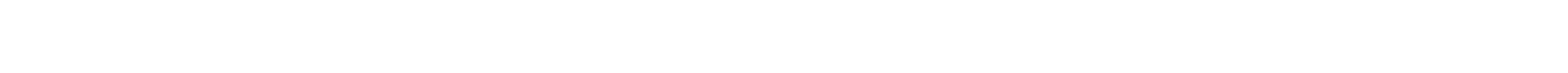
والتوسعات اللسكلنية الهسقبلية "(11).

كما تهرف بأنها "مجموعة من الأساليب واللارق التي لها مظلور جغرلي في صميم التعليم حيث تبف الخرطة عل معلوملت مكلنية Spatial ترتطا مع المعلوملت الخاصة المميزة لامكل Attribute Information الخربلة كما تتضنمن معلوملت إضلفية عن ملامح وسمات المظلقة أو الغاليم المراد رسم خرطة 
خلاصة ماسبق أن الخرولة المدرسية وسيلة وليست غلية، فهي وسيلة لتفير المناخ التروي

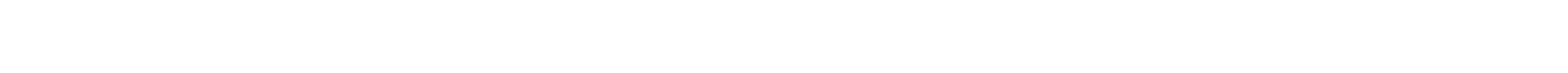
فمع القعم العلي والتكنولوجي اللسرع لم تهد المدرسة هي المكل الوحيد لكتسلب المعرفةبوتنمية المهارل وإنماشاركت معها العيدمن مؤسسك المجتمع بشكل مبلثر وغيرمباثد ـر، ول م يعء 2

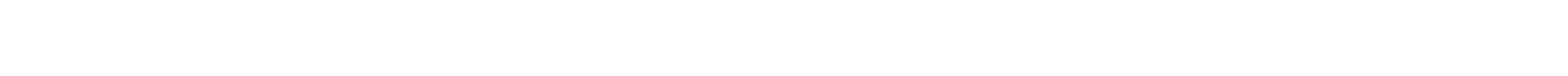
ملق مبدأ" التعليم المستمر لؤ النعليم مدي الحياة ".

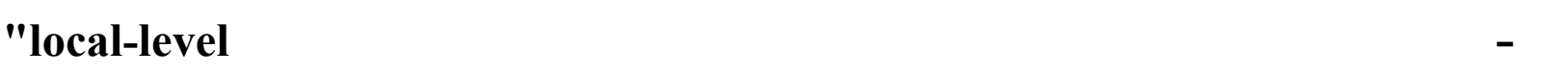
: planning"

هنك عددمن المبررات للأخذ بأسلوب الخربة المدرسية ومنها (Ir):

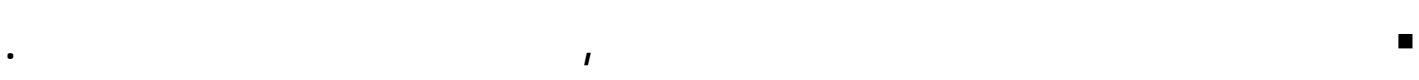

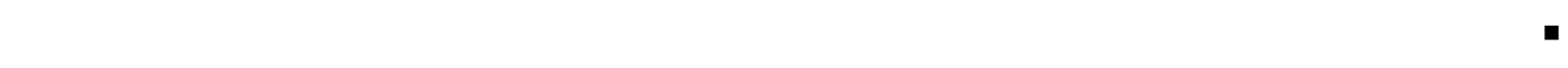

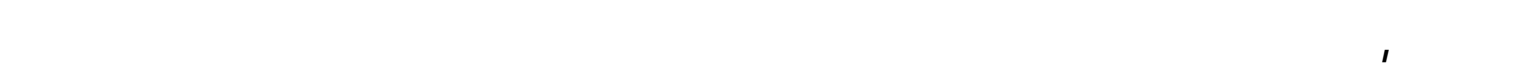
المسقل.

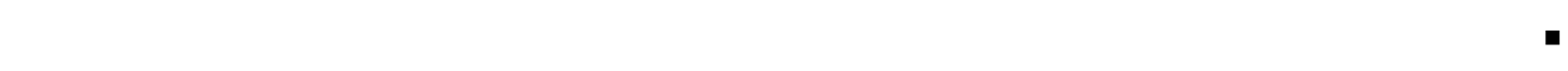
مظاقة.

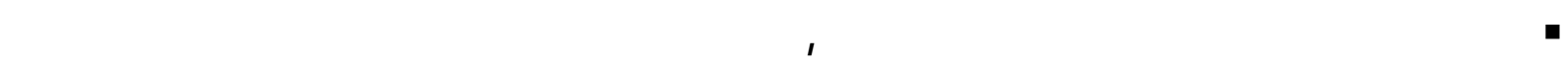
القائمن عل التمليم ومففيه ف تحسيد موفع النمو النمليف وهوفع المداس ف المنلاق المختلفة.

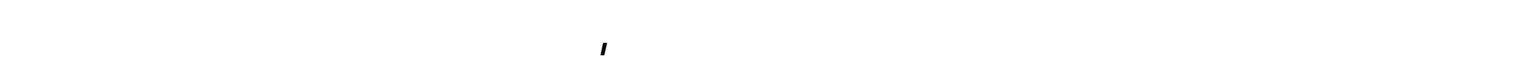

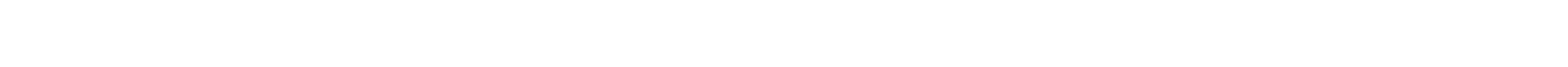

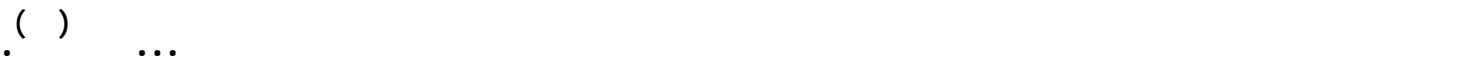
ج - أنده الخربلة المدرسية :

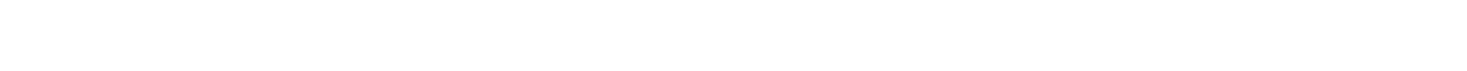
النظيا النعليم المصغر "micro planning 'الفي الأهده الآنية (10) : • ت توفير النعليم الأسلمي لجمبع الألفلفيسن المدرسة.

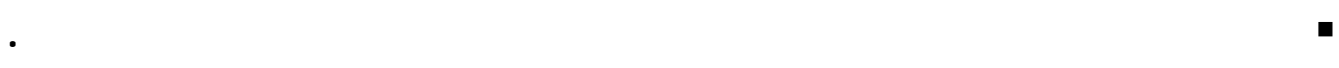

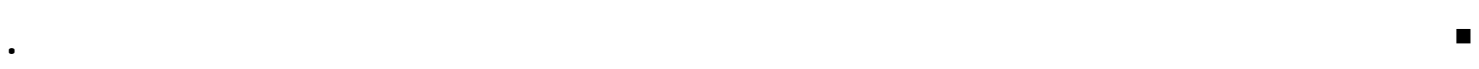




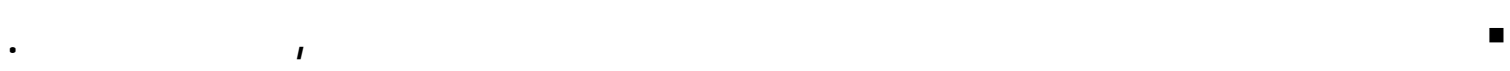

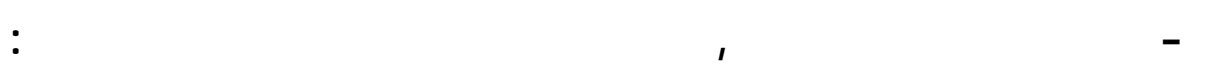

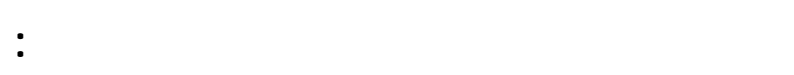

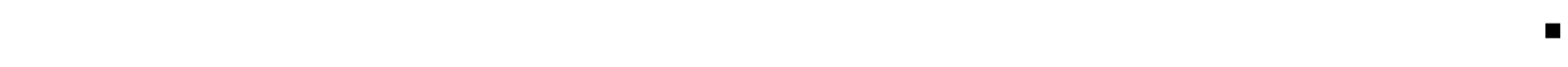

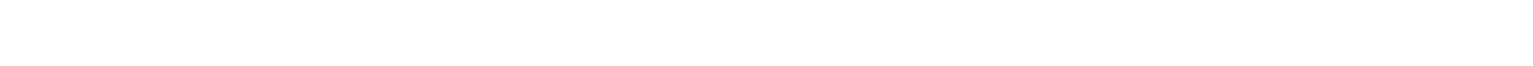
زمنية محصة (17)

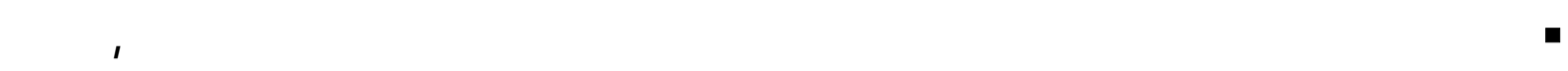

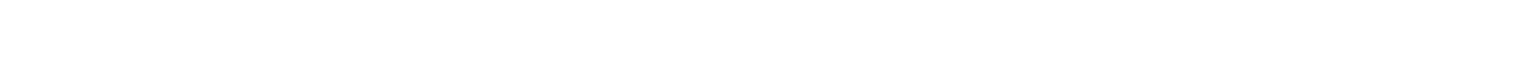
المرحلة السلقة • إنالة الفرصة لمشاركة أعضاء اللطلة المحلية في النظليا, وذك في ضوء الحتيلجلت وأهيل

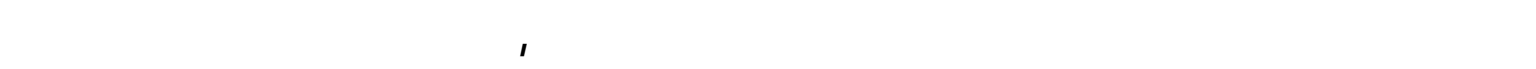

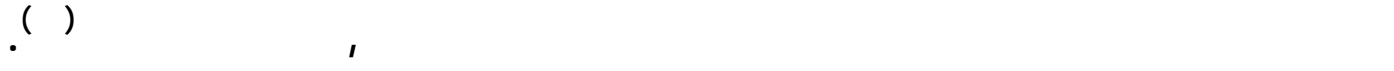

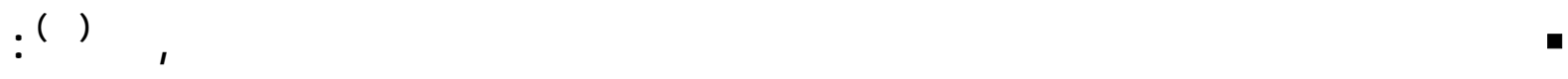

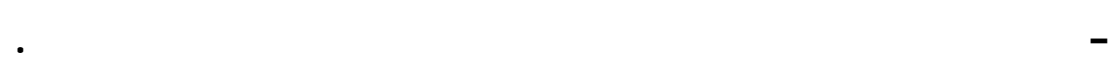
- مشكلي المسوب والنسرب ولإعالة والهرب وتلف مستوى النحصل.

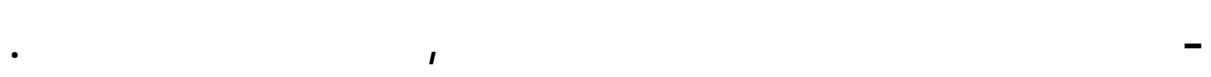
هـ ـ -مطالبلت إعداد الخربلة المدرسية:

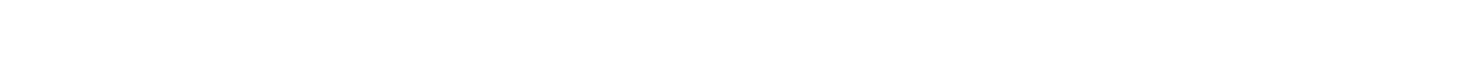

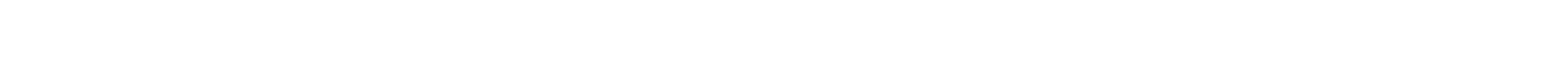

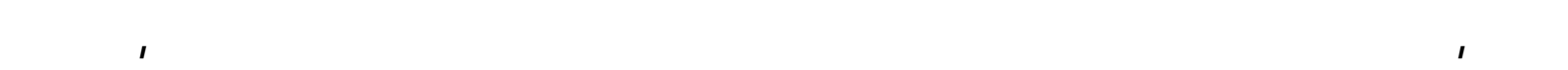

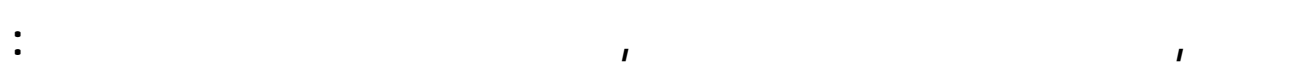

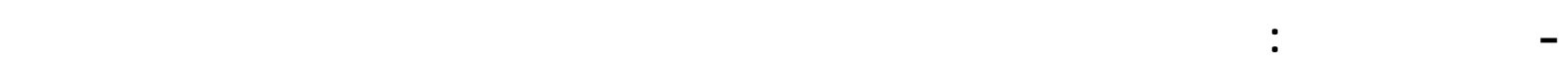

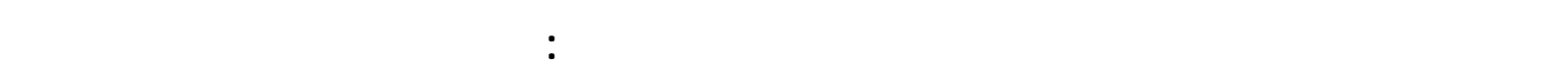
في مرحلة معينة .الخ الخ (r).

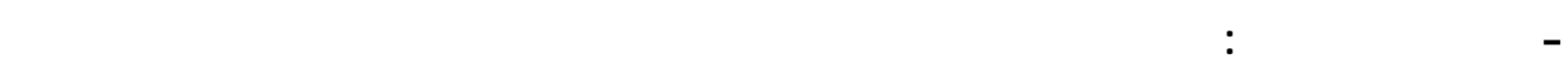
والحصائيلت بيلنية (ri)

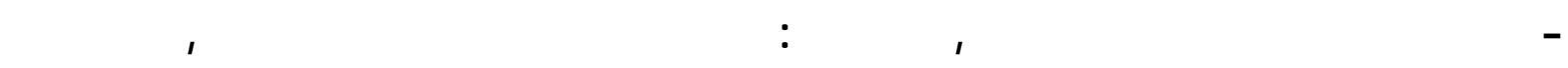

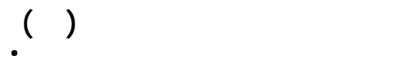

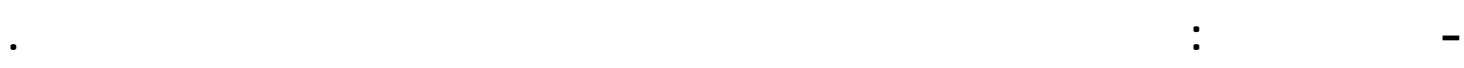




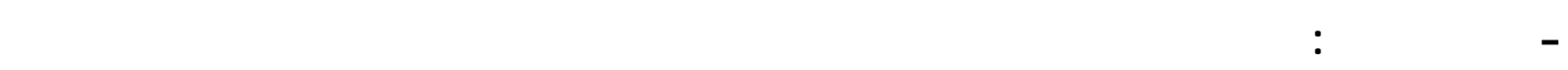

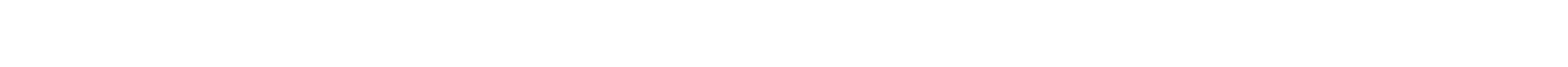

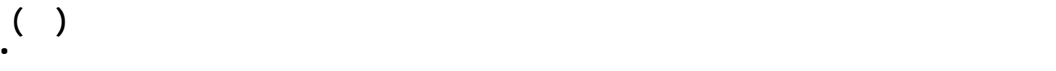

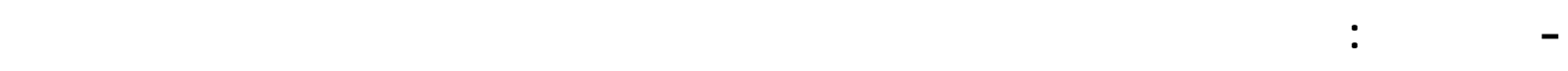

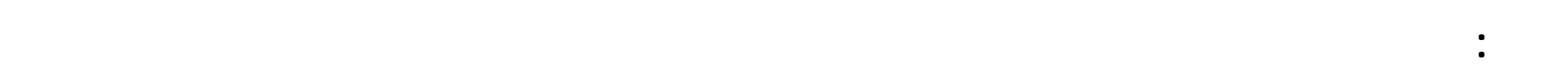

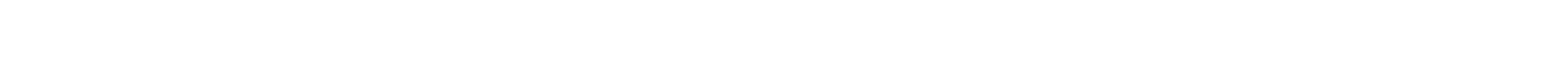

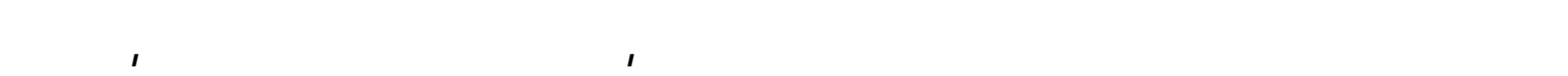

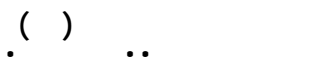

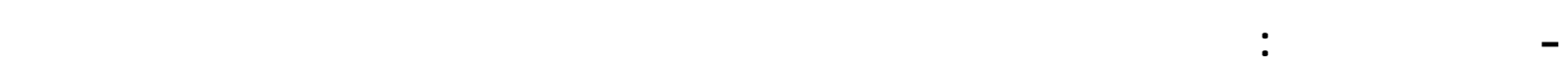

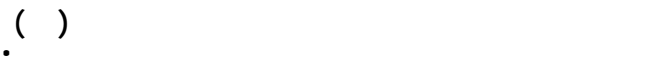

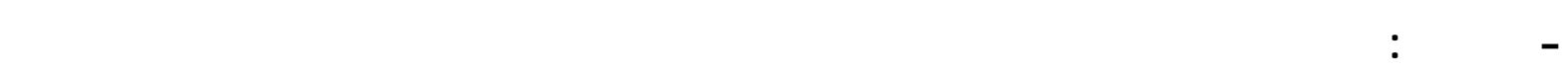

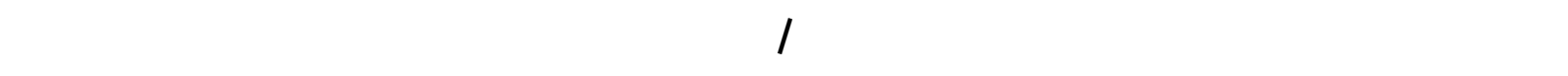

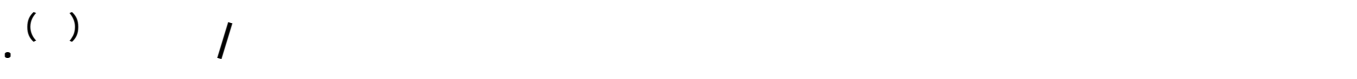

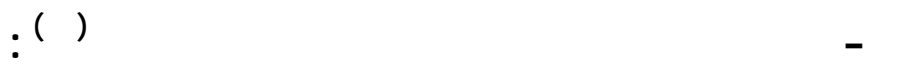

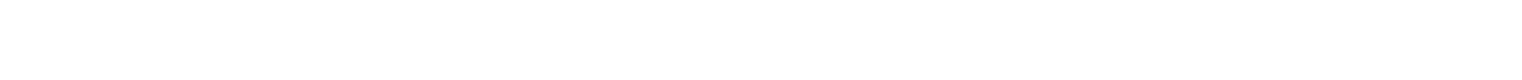

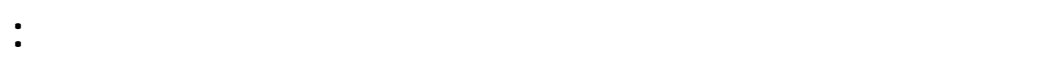

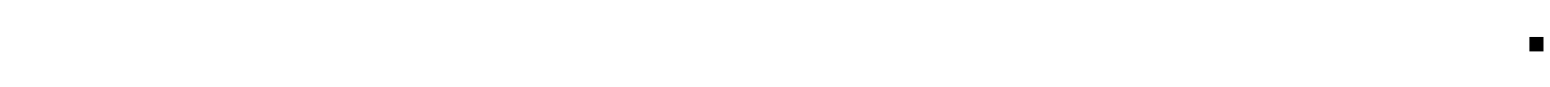

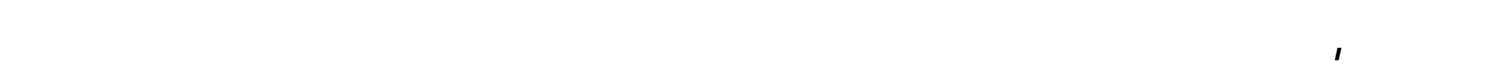
المربسية, خامة في الدط النامية.

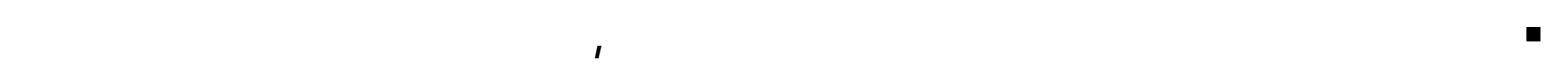

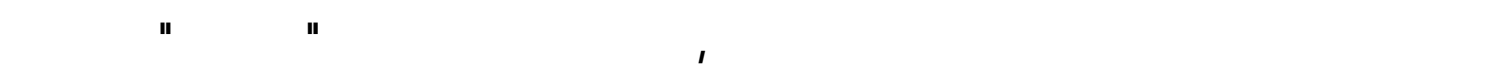
ورجة وعيهم بأهمية هنه الرملسلت.

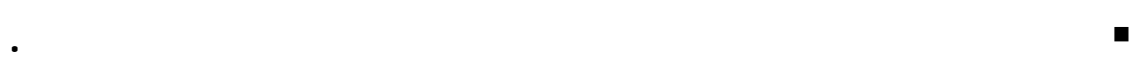
ثلنياً : الإبار المملي المرلسة

مرالمل وضع الخربلة المدرسية:

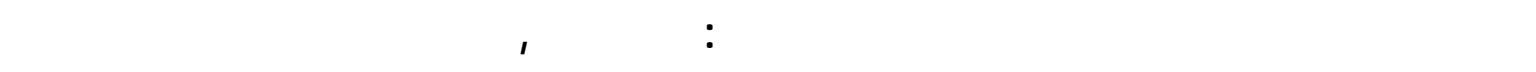

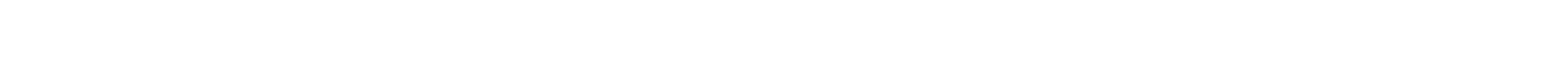

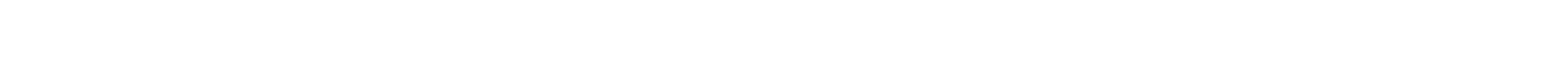
فيماليل : 


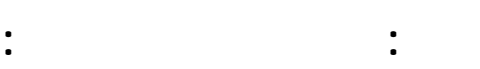

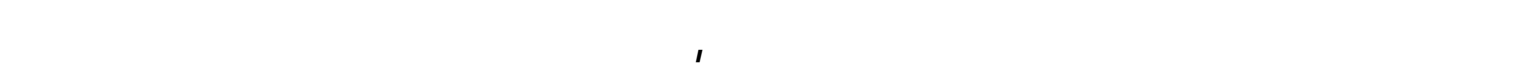

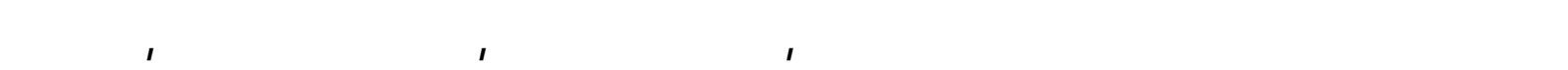

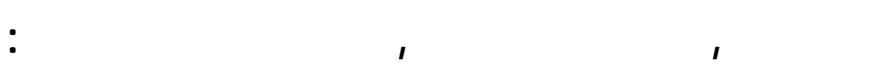

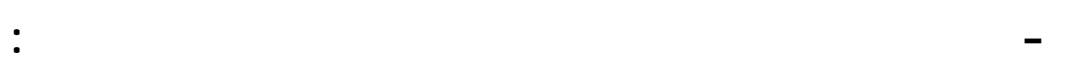

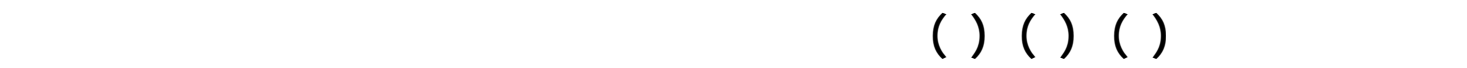

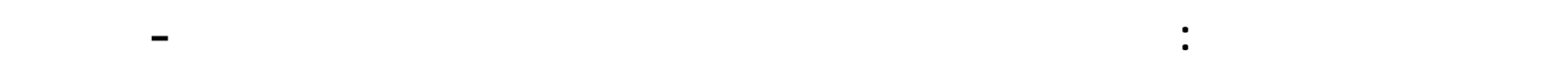

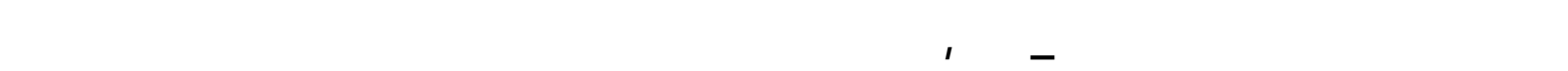
وفصل ذك فيما يل :

$$
\text { (1) جطر }
$$

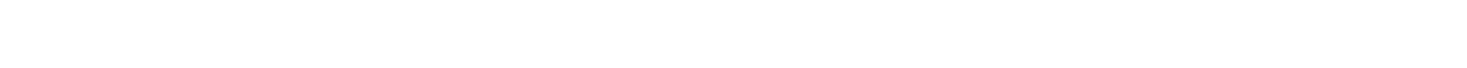

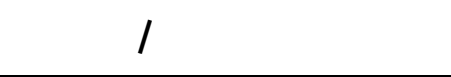

\begin{tabular}{|c|c|c|c|c|c|c|c|c|c|}
\hline \multirow{2}{*}{ 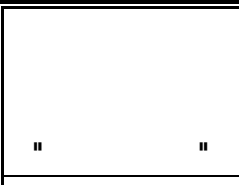 } & \multirow[b]{2}{*}{ لالاتنمالئيم المكلي } & \multirow{2}{*}{ 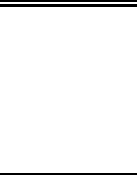 } & \multicolumn{6}{|c|}{ 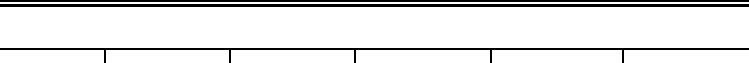 } & \multirow[b]{2}{*}{ ل ل عركز } \\
\hline & & & $\%$ & الإص & $\%$ & إنك & $\%$ & ذكهر & \\
\hline \multirow{7}{*}{ \%१। } & \multirow{7}{*}{ ( } & عА,r. & عץ, & $\begin{array}{c}r \cdot \boldsymbol{r} \\
\boldsymbol{r}\end{array}$ & ع0 & 977£ & દז,ع0 & I.ru & لمش ل ال \\
\hline & & $\varepsilon 0, r$. & $\mathbf{I \Lambda , 0}$ & АЕ११ & $\mathbf{~ I A}$ & rАEץ & 19 & $\varepsilon 707$ & بئرلمبد \\
\hline & & $\varepsilon 7,7$. & $\mid \varepsilon, \Lambda$ & TVVE & $\mid \varepsilon, V$ & rIVI & $1 \varepsilon, V_{0}$ & M.r & لشبيخ زويد \\
\hline & & $\varepsilon 7,9$ - & $\mathbf{I}, \mathbf{r}$ & Arqu & $\mid \Lambda, \varepsilon$ & ल१हा & $\mathbf{I A , r}$ & 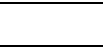 & ف \\
\hline & & M,q. & $\mathbf{r , 0}$ & ITI & $r, V$ & 090 & $\varepsilon, r$ & $1.1 \mathrm{~V}$ & المسفة \\
\hline & & $\varepsilon \Gamma, \Lambda \cdot$ & $1, \mu$ & ovv & $1, r$ & rEV & $1, \varepsilon$ & Mr. & I] \\
\hline & & $\varepsilon 7, \mathbf{v}$. & $1 \ldots$ & $\begin{array}{c}\varepsilon 0 M \\
T\end{array}$ & $1 \ldots$ & זרדוr & $1 \ldots$ & ૨દદરદ & الإلصآ \\
\hline
\end{tabular}

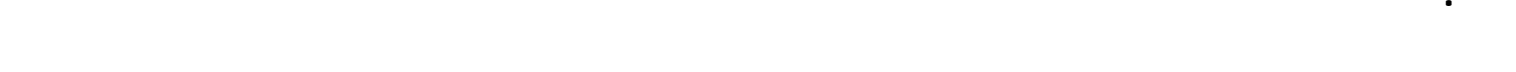
المصري: جط (r)

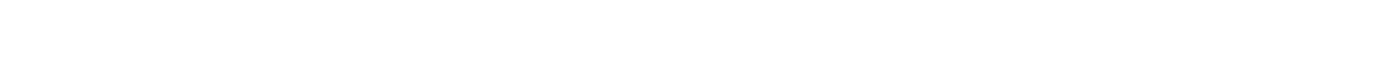

\begin{tabular}{|c|c|c|c|c|c|c|}
\hline \multicolumn{6}{|c|}{ عدد التلاميذ } & \multirow{2}{*}{ لركر } \\
\hline$\%$ & $d]$ & $\%$ & ر ف & $\%$ & هضر & \\
\hline $1 \ldots$ & זוץ. & 1,00 & r.9 & १И,ह0 & 19VTr & لالستش \\
\hline $1 \ldots$ & Аह११ & $7 V, 07$ & OVER & 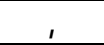 & rVov & بئر للجد \\
\hline $1 \ldots$ & TVVE & 09,1 & $\varepsilon \cdots$ & $\varepsilon \cdot, q$ & rVYr & الثبخ زوبد \\
\hline $1 \ldots$ & תו" & $\varepsilon r, \mu$ & roo. & $\mathbf{O V}, \mathbf{V}$ & 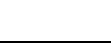 & فح \\
\hline $1 \ldots$ & $171 \%$ & $\mathbf{\Lambda V}, \boldsymbol{\varepsilon}$ & $1 \varepsilon .9$ & $1 \times, 7$ & r.r & الحسمة \\
\hline $1 \ldots$ & ovv & $0 \cdot, 1$ & rA9 & $\varepsilon १, १$ & rMM & J] \\
\hline $1 \ldots$ & ع0MA7 & MY,Y & 10\%.. & $77, v$ & r.017 & $\square \square$ \\
\hline
\end{tabular}

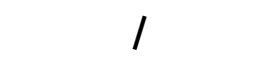


الكتلب اللحصائ السنوي لمحانلقشملسسيناء علم V - . r، مصرسسلق.

$$
\text { (ع) (ع) }
$$

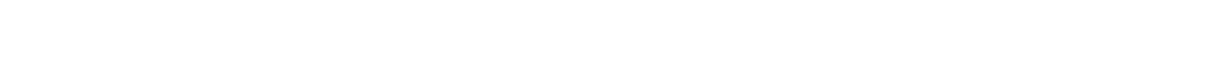

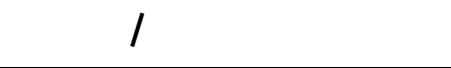

\begin{tabular}{|c|c|c|c|c|c|c|c|c|c|}
\hline \multicolumn{3}{|c|}{ كاda dede } & \multicolumn{3}{|c|}{ عدد الهمرل } & \multicolumn{3}{|c|}{ عدد تلاميذ التهليم الابتناك } & \multirow[t]{2}{*}{ إلركز } \\
\hline$\square \square$ & ف & هضر & \begin{tabular}{l|l}
$\square$ \\
\end{tabular} & ر) & هنر & $\square \square$ & ف) & هضر & \\
\hline m & 1. & rV & 071 & r. & orl & rו..r & r.9 & 19Vrr & الوش \\
\hline T & $\boldsymbol{T}$ & $\varepsilon \cdot, 0$ & мrq & rו & 7 & ^६११ & OVEr & rvov & بئر المبد \\
\hline r⿷ & $r \cdot, V$ & rI,q & rA. & $19 \%$ & $\mathbf{A V}$ & TVVE & $\varepsilon \cdots 1$ & rVvr & الثبيخ زويد \\
\hline $\boldsymbol{\mu \varepsilon}$ & P, 1 & YA,V & reo & IT. & Iro & איז & roo. & દ^દז & فे \\
\hline $\mathbf{v}$ & 7,0 & $M, 0$ & TrE & rio & 9 & אודו & $1 \varepsilon .9$ & r.r & الهسة \\
\hline 9 & 7,0 & 19 & 09 & $\varepsilon \varepsilon$ & 10 & ovv & rı9 & rM & ل] \\
\hline & $I V, V$ & r $7, v$ & 1794 & אדר & Aro & E0MT & lor.. & r.017 & الإل|| \\
\hline
\end{tabular}

المصري

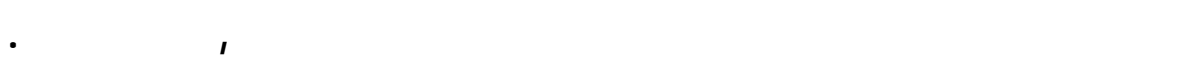

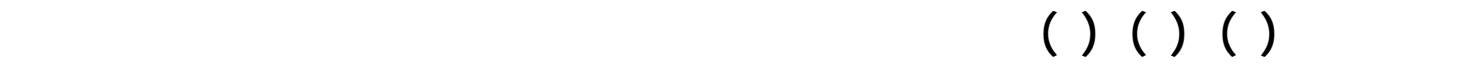
شربحة كبيرةمن اللسكلن تطل الل و\%، ولنها موزعة عل مرلكز المحلئة اللستة، والذ عبة

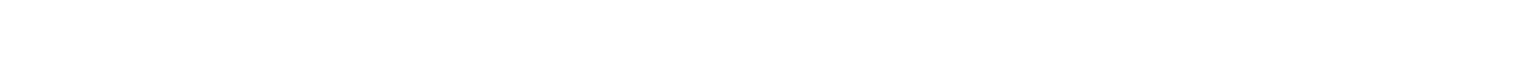

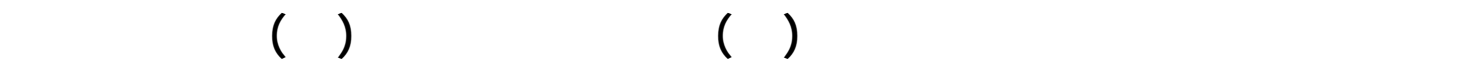

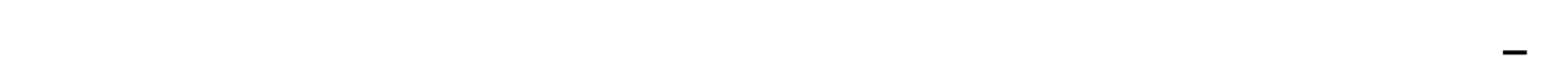

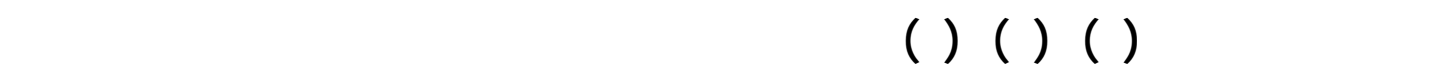
عسناء

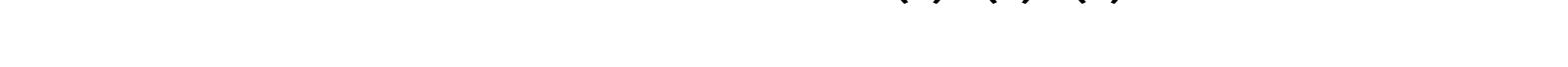

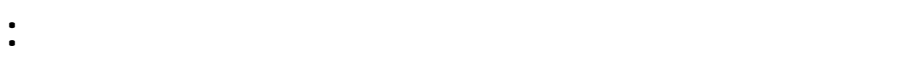
(0) (0)

\begin{tabular}{|c|c|c|c|c|c|c|}
\hline \multicolumn{6}{|c|}{ عدد المبسل } & \multirow{2}{*}{ الهركر } \\
\hline$\%$ & प】 & $\%$ & إلتك & $\%$ & ذكور & \\
\hline \%1.. & IEVA & \%ד & 9\%1 & \%rV & OEV & للبشش \\
\hline$\% 1 \ldots$ & $\varepsilon 0 \AA$ & \%"7 & 170 & \%าद & rq & بئر لبد \\
\hline$\% 1 \ldots$ & 190 & \%દ0,乏 & ITE & $\% 0 \varepsilon, 7$ & 171 & الثبخ زويد \\
\hline$\% 1 \ldots$ & אדr & \%ع। & $1 \cdot V$ & $\% 09$ & 100 & فح \\
\hline$\% 1$. & 119 & $\% r, 7$ & 0 & \%qV,દ & 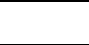 & المستة \\
\hline \%1... & r7 & $\% 11,1$ & $\varepsilon$ & $\% \mathbf{M}, \mathbf{9}$ & rT & ] \\
\hline \%1.. & rVIA & \%६१,0 & IFET & $\% 0 \cdot, 0$ & IrVr & पلإلإل \\
\hline
\end{tabular}

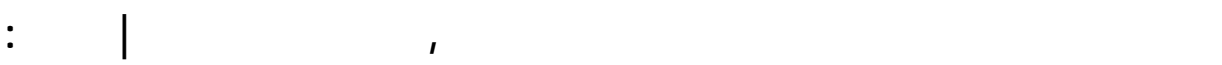


ll

الكتلب الحصائ للسنوي لمحالفةشملسسيناء علم V - . - امركز المعلوملت ودعم النخاذ الفرار

بالمحلثلة.

(7) (1)

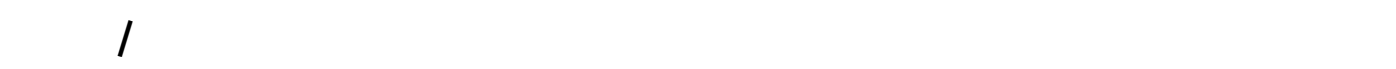

\begin{tabular}{|c|c|c|c|c|c|}
\hline ميب إلمون من الثلاميذ & ميب إلمون هن الهمط & الثلميذ & علد & [عدوس & إلركز \\
\hline $1 \varepsilon$ & $\boldsymbol{\mu}$ & $r \ldots r r$ & 071 & IEVA & لمشش المش لم \\
\hline 19 & 1 & А६१९ & mq & $\varepsilon 0 \Lambda$ & 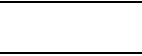 \\
\hline$r \mu$ & 1 & TVVE & r.. & 190 & الثبخزويد \\
\hline rr & $\mathbf{I}$ & Arqr & TEO & זורז & ف \\
\hline 9 & 1 & $171 \%$ & ITE & 119 & العسة \\
\hline $1 \varepsilon$ & 1 & ovv & 09 & m7 & $\pi$ \\
\hline إن:وط 19 & إلوبط I ا & ह0ММт & 179 & PVIA & الإبها \\
\hline
\end{tabular}

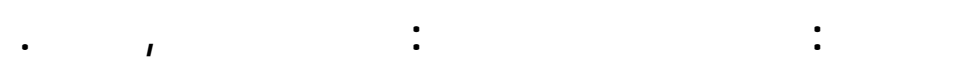
جدط) (v)

المجز والزباةف هيئل الثربس عل هـتوى جمبع الإدارت النعليمية بالمحلثلة

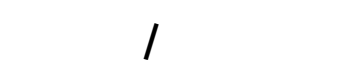

\begin{tabular}{|c|c|c|c|c|c|}
\hline الزباة & عسبة المجز (\%) & للهجز & المجود & لهلالوب & الميل \\
\hline - & $\%$ & $r 77$ & 1199 & Iعєo & مموصفل \\
\hline- & $\%$ \% & rEA & rм9 & 7rv & الةعرية ولين هاعلح \\
\hline- & $\% r \cdot, 0$ & $\varepsilon q$ & 19. & M"q & رلرطلت الجمالية \\
\hline - & $\% \varepsilon \cdot, 7$ & ITV & 107 & אוץ & ربلنيلت \\
\hline- & $\% \varepsilon 1,0$ & 90 & IrE & M9 & عله \\
\hline - & \%ع. & 111 & $17 \varepsilon$ & rvo & لة إلإزة \\
\hline - & $\% \mathbf{M}, \mathbf{\Lambda}$ & IAr & $\boldsymbol{\mu}$ & r.o & حسب آ] \\
\hline- & $\%$ vi & Iro & $r \varepsilon$ & IVV & 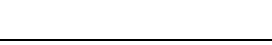 \\
\hline- & $\% 0 \varepsilon$ & 99 & $\Lambda \varepsilon$ & IAr & [ل]صني \\
\hline- & $\%$ \%т,0 & IIV & v. & IAV & [ل لذريلي \\
\hline - & $\% 70, \Lambda$ & 119 & १ & raV & 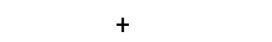 \\
\hline - & \%१। & IV9 & IV & 197 & مكنبلت \\
\hline- & $\% \Lambda$. & IAY & Eo & MTV & تربيةربلنية \\
\hline- & \%१। & 119 & $\mathbf{1 n}$ & r.v & تريةموبقية \\
\hline - & \%^० & $\mathbf{I} \varepsilon$ & r & דוץ & تريةفية \\
\hline - & $\%$ vI & Ir. & or & iar & صيالة وترميمات \\
\hline - & \%ع^ & ro.ह & PV.0 & or.9 & الע口 \\
\hline
\end{tabular}

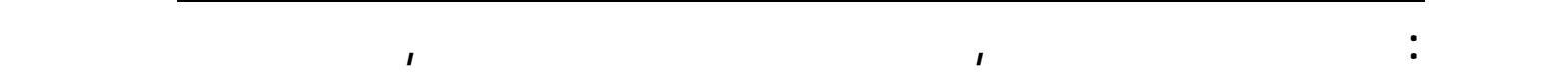

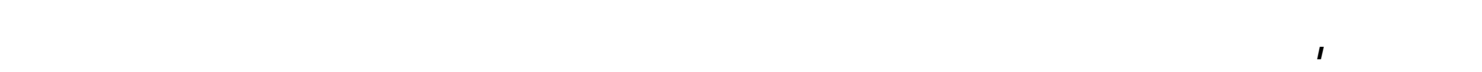

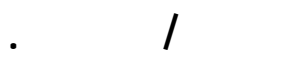


من الجدالل (0)، (7)، (V) السلقة يقم ملاخلة أن أعل نسبة من المدرسبن موجودة فمركز

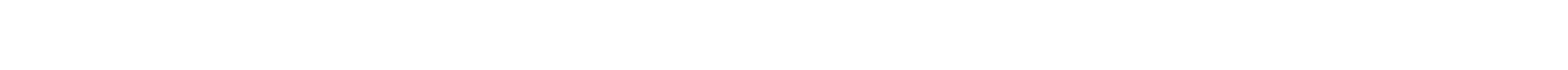

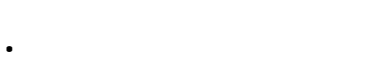

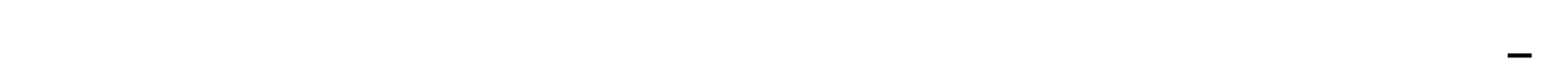
عشملسuيناء

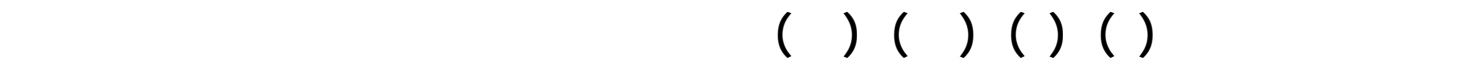

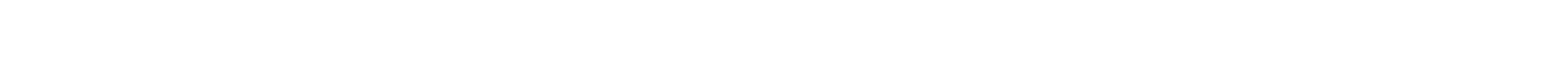

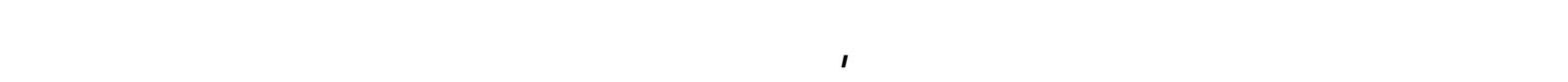
النعليمية والمرالق الصحية، وفهبل ذك فيما يل : (A)

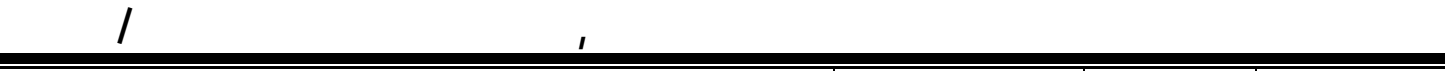

\begin{tabular}{|c|c|c|c|c|c|c|c|c|}
\hline \multicolumn{5}{|c|}{ تبعية المدوبسة } & \multicolumn{2}{|c|}{ الليئة البهرالية } & & \\
\hline 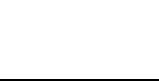 & للهل & 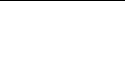 & للف & رسي & حضر & رف & الداعوس & المركز \\
\hline & 1 & & $r$ & हo & $\varepsilon v$ & 0 & or & الهرشن \\
\hline 1 & - & - & - & $\varepsilon r$ & 7 & rv & $\varepsilon r$ & بئر المبد \\
\hline- & - & - & $\overline{-}$ & $\begin{aligned} \text { ra } \\
\text { ra }\end{aligned}$ & $\Lambda$ & r. & ra & الثبخ زوي \\
\hline- & - & - & - & $\varepsilon$ & ir & $\frac{11}{\varepsilon 1}$ & $\begin{array}{l}r \Lambda \\
\varepsilon \varepsilon \\
\varepsilon \varepsilon\end{array}$ & الالهئة \\
\hline$r$ & 1 & $r$ & $r$ & $\frac{11}{r-1}$ & $\begin{array}{l}r \\
v q\end{array}$ & $\frac{\Lambda}{\text { Irv }}$ & $\frac{11}{\mathrm{r} 17}$ & $\frac{h_{i}}{d_{0}}$ \\
\hline
\end{tabular}

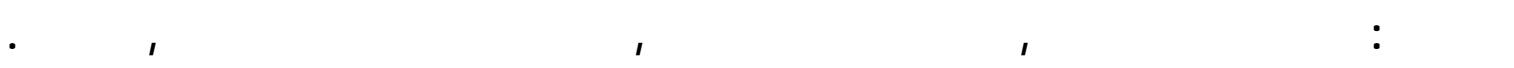

(9) ج)

تصنيف مداوس التعليم الابدائ وقا لعد الأبنية الق يشغلها, وملكية المبف وحالنه لله

$$
r \cdot \mathrm{r} / \mathrm{r} \cdot \mathrm{T}
$$

\begin{tabular}{|c|c|c|c|c|c|c|}
\hline \multicolumn{2}{|c|}{ حالة المبف } & \multicolumn{2}{|c|}{ ملكية المبف } & \multirow{2}{*}{ الأبنية } & \multirow{2}{*}{ المداوس } & \multirow[t]{2}{*}{ المركز } \\
\hline غير صالح & صالح & مؤجر & גكوي & & & \\
\hline- & or & - & or & or & or & الربش \\
\hline - & ع & - & ع & $\varepsilon \mu$ & $\varepsilon \boldsymbol{\varepsilon}$ & بئر العبد \\
\hline- & rᄉ & - & r & rA & M & الشبخ زوبد \\
\hline - & rA & - & ra & rA & ra & رفح \\
\hline- & $\varepsilon \varepsilon$ & - & $\varepsilon \varepsilon$ & $\varepsilon \varepsilon$ & $\varepsilon \varepsilon$ & الهسنة \\
\hline - & 11 & - & 11 & 11 & 11 & thi \\
\hline - & דוr & - & זוז & & rוד & الإجمالي \\
\hline
\end{tabular}

المصرر:محانلمشملسشيناء,مديرية التربية والتعليم ,المصر السلق. 


\section{جطط - (1)}

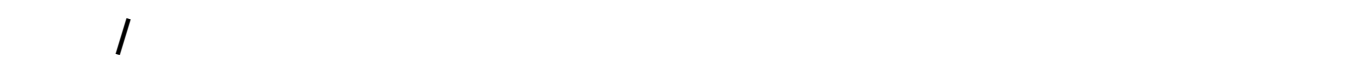

\begin{tabular}{|c|c|c|c|c|c|c|}
\hline الملاعب & الوش & المكنبلت & الأفنية & المعالل & المداوس عدد & المركز \\
\hline or & - & $\varepsilon r$ & or & or & or & العربش \\
\hline$\varepsilon \boldsymbol{\varepsilon}$ & - & $\mu \varepsilon$ & $\varepsilon \boldsymbol{\varepsilon}$ & $\varepsilon \boldsymbol{\varepsilon}$ & $\varepsilon \boldsymbol{\varepsilon}$ & بئر العبد \\
\hline rA & - & rE & ra & ra & ra & الشبخ زوبد \\
\hline ra & - & rع & ra & rA & ra & رفح \\
\hline$\varepsilon \varepsilon$ & - & $1 \Lambda$ & $\varepsilon \varepsilon$ & $\varepsilon \varepsilon$ & $\varepsilon \varepsilon$ & الهسنة \\
\hline 11 & - & $\varepsilon$ & 11 & 11 & 11 & thin \\
\hline rוד & - & 107 & rIT & rIT & rוד & الإجمالل \\
\hline
\end{tabular}

المصرر:محالغلقشملسسيناء,مديربة التربية والتعليمرالمصر السلق.

\section{(11) جطو (1)}

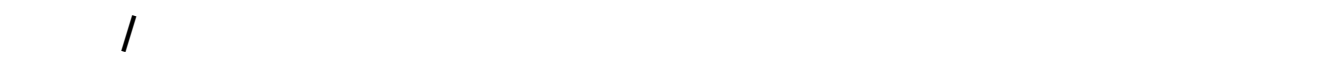

\begin{tabular}{|c|c|c|c|c|c|c|c|}
\hline \multicolumn{2}{|c|}{ دورات المياه/صرف } & \multicolumn{2}{|c|}{ الكهرباء } & \multicolumn{2}{|c|}{ مياه الشرب } & \multirow{2}{*}{ عدد المدارس } & \multirow{2}{*}{ المركز } \\
\hline غير صالحة & صالحة & لا يوجد & يوجد & غير متوفرة & متوفرة & & \\
\hline 一 & or & 一 & or & 一 & or & or & العريش \\
\hline - & $\varepsilon r$ & - & $\varepsilon r$ & - & $\varepsilon r$ & $\varepsilon r$ & بئر العبد \\
\hline 一 & $r \wedge$ & 一 & $\mu \wedge$ & 一 & $r \wedge$ & $r \Lambda$ & الشيخ زويد \\
\hline- & $r \wedge$ & - & $r \wedge$ & 一 & rA & $r \wedge$ & رفح \\
\hline - & 纟 $\leqslant$ & 一 & \& \& & 一 & $\leqslant$ \& & \& & الحسنة \\
\hline - & 11 & 一 & 11 & 一 & 11 & 11 & 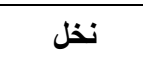 \\
\hline - & Y19 & - & Y17 & - & Y19 & Y17 & الإجمالي \\
\hline
\end{tabular}

المصر:محاثلقشملسسيناء,مديربة التربية والتحلم, المصر اللسلق.

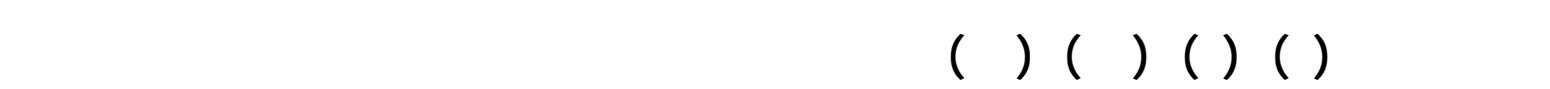

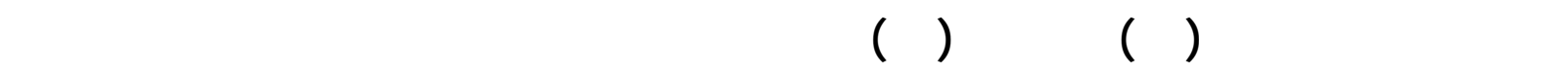

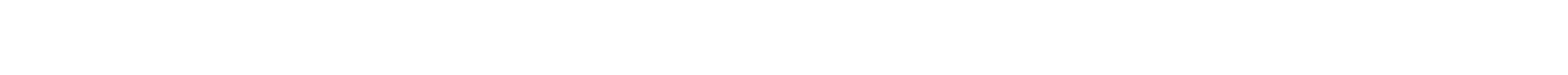

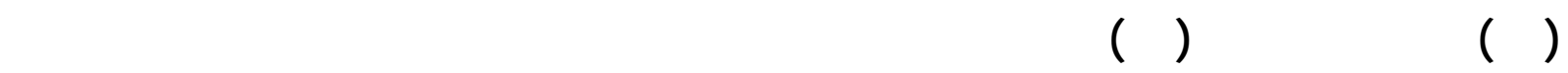

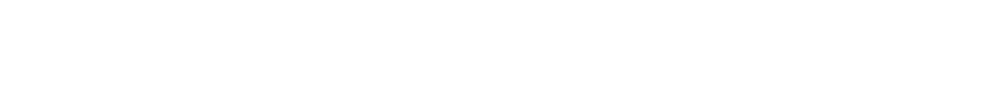


المرحلة الثلنية 'مرحلة الننبؤلت ولالمقللت:

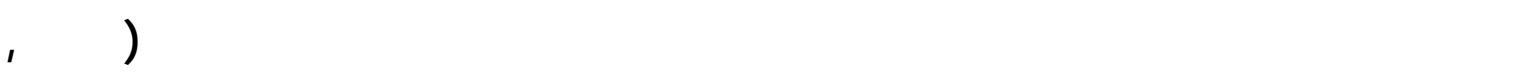

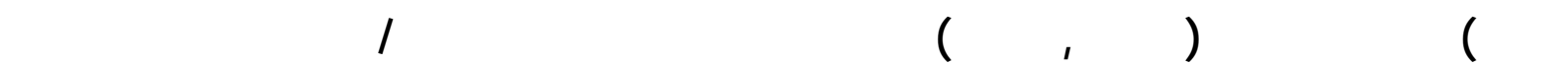

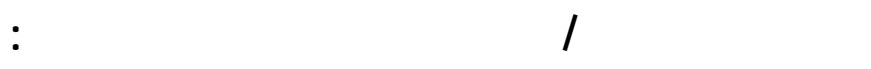

أ - قديرات أعدالاطلاب التعليم الابتدائ الوسم عل مستوى محالفالقشملسسيناء :

يسترض الجرط الآت أعداد الماللب المترقمة بالتعليم الابتدائ عل مستوى محاثلةشمل

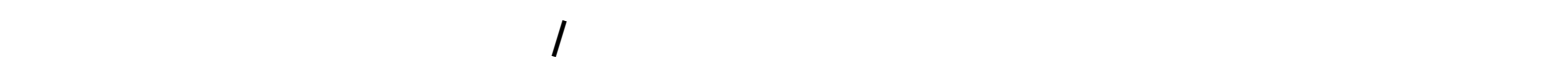

$. r \cdot 1 \mathrm{~V} / \mathrm{r} \cdot 17$

(IT) جطط (1)

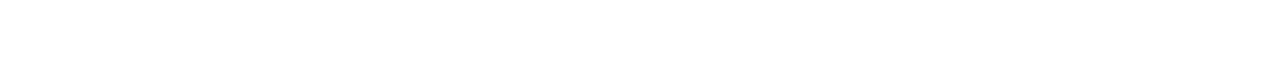

\begin{tabular}{|c|c|c|c|c|c|c|c|c|c|c|c|c|c|c|}
\hline \multicolumn{2}{|c|}{ لالجمال } & \multicolumn{2}{|c|}{ الساس } & \multicolumn{2}{|c|}{ الخلس } & \multicolumn{2}{|c|}{ الرلع } & \multicolumn{2}{|c|}{ الثالث } & \multicolumn{2}{|c|}{ الثالي } & \multicolumn{2}{|c|}{ الأل } & \\
\hline I & j & I & j & I & j & I & j & I & j & I & j & I & j & \\
\hline$r \mid \leqslant 1 r$ & $r \leqslant 10 \wedge$ & TrYT & Y94r & $r \leqslant \wedge 4$ & ra०4 & $r \leqslant 0 q$ & rqvर & $r v . q$ & ए१११ & \&YOV & \&AYY & 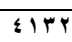 & \&ะY & $r \ldots \Lambda / r \ldots v$ \\
\hline YY.00 & $r \leqslant \wedge \wedge r$ & $r \leqslant \leqslant \leqslant$ & r.or & $r \otimes q 1$ & $\varepsilon \cdot v_{0}$ & royr & $\varepsilon .9 V$ & rNIV & $\$ 119$ & $\varepsilon r \wedge \theta$ & $\sum 9 \wedge 1$ & \&Y०१ & $\{009$ & $r \ldots q / r \ldots \wedge$ \\
\hline FYYIV & royrq & YO1A & 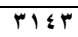 & r991 & §19V & rTV. & $\varepsilon Y Y$. & rapr & $\leqslant Y \leqslant Y$ & $\$ 019$ & 015. & $\varepsilon \Psi \wedge \varepsilon$ & $\$ 790$ & $r \cdot 1 \cdot / r \ldots q$ \\
\hline PrTQA & אודף & roqr & TrMA & $r \wedge .9$ & ETYT & $r v \wedge$. & $\varepsilon \Psi \leqslant V$ & $\varepsilon .0$ & $\varepsilon r v$. & \&YOY & OYA & $\leqslant 010$ & \&AY & $r+11 / r \cdot 1$. \\
\hline$r \leqslant 1 \ldots$ & pVIq. & YTVI & DTro & raYr & «\&OY & rरq4 & $\varepsilon \leqslant V V$ & $\varepsilon|V|$ & $£ 0.1$ & हจ१। & $0 \leqslant \leqslant$ & $\$ 701$ & धq৯1 & $r \cdot \mid r / r \cdot{ }^{\prime}{ }^{\prime}$ \\
\hline TENYT & rA.. & rVOI & $r \leqslant r 0$ & 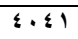 & $\varepsilon 0 \wedge 4$ & $\varepsilon .1$ & $\leqslant \pi$ & \& Yq4 & \&4T4 & \&9४० & 09.7 & $\leqslant \vee q$. & $01 \% 1$ & $r \cdot I T / r \cdot I r$ \\
\hline ro04h & $Y \wedge \wedge \leq 4$ & TAYT & rork & $\$ 17 Y$ & $\xi V Y \xi$ & \&ाT. & $\varepsilon \vee 0_{0}$. & $\leqslant \leqslant \varphi_{0}$ & $\xi V_{V}$ & $0 . \wedge r$ & OVV $\varepsilon$ & 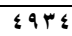 & OYAO & $r+1 \leqslant / r+1 r$ \\
\hline TMTro & rqvणl & rq१A & MY & EYAV & \&ATo & $\leqslant$ ros & $\varepsilon \wedge q \uparrow$ & $\Leftrightarrow 00 \wedge$ & $\varepsilon 91 \wedge$ & OrTy & $09 \leqslant 1$ & $0 . \lambda r$ & $0 \leqslant \leqslant T$ & $r .10 / r+1 \leqslant$ \\
\hline rVIro & $r \cdot 7 \cdot r$ & $r \ldots r$ & rvor & «\$17 & 0.11 & $\varepsilon$ \&NY & 0.49 & $\leqslant 790$ & 0.44 & orar & $71 \times 4$ & OrTs & $04 . \mathrm{V}$ & $r .1 \% / r+10$ \\
\hline rVqrq & rlorl & $r .97$ & rᄉห4 & $\leqslant 0 \leqslant \Lambda$ & $014 \%$ & $\leqslant 014$ & 019. & 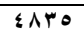 & OYIA & $000 \leqslant$ & .וזי & orq1 & OVVO & $r+1 V / r+17$ \\
\hline
\end{tabular}

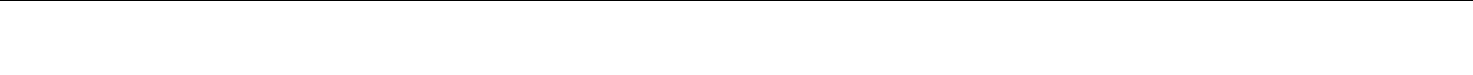

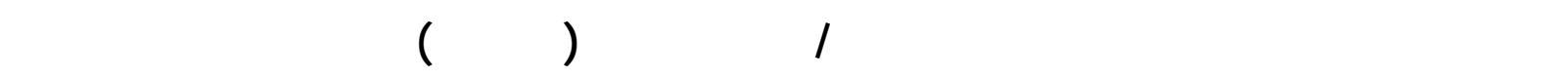

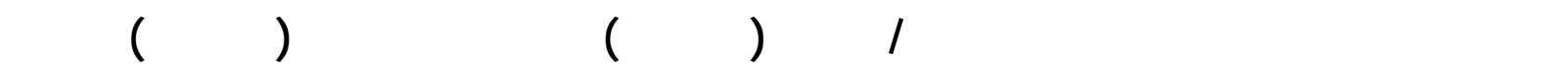

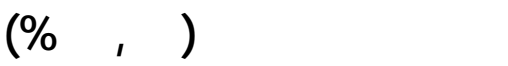




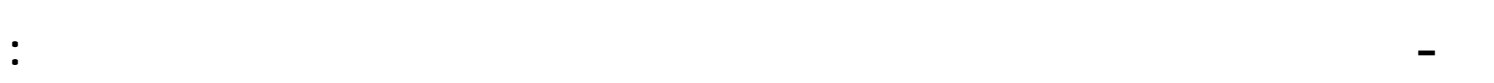

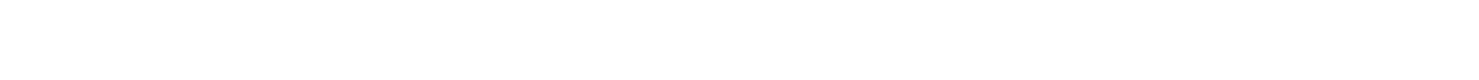

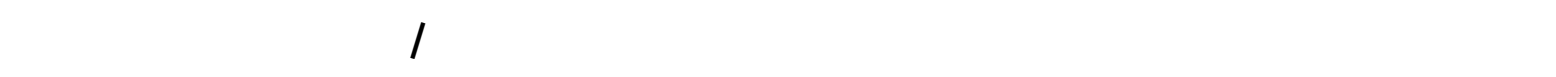

$$
\text { المستهف } 17 \text {. IV/T - م. }
$$

$$
\text { (Ir) (11) }
$$

\begin{tabular}{|c|c|c|c|c|c|c|c|c|c|c|c|c|c|c|}
\hline \multicolumn{2}{|c|}{ الاجمالى } & \multicolumn{2}{|c|}{ السادس } & \multicolumn{2}{|c|}{ الخامس } & \multicolumn{2}{|c|}{ الرابع } & \multicolumn{2}{|c|}{ الثالث } & \multicolumn{2}{|c|}{ الثاني } & \multicolumn{2}{|c|}{ الأول } & \multirow[t]{2}{*}{ الصف } \\
\hline 1 & $\dot{j}$ & 1 & $\dot{j}$ & 1 & $\dot{j}$ & 1 & $j$ & 1 & $j$ & 1 & $j$ & 1 & $\dot{j}$ & \\
\hline $11 \varepsilon$ & 107 & $V$ & $\Lambda$ & 10 & ir & ro & $r \leqslant$ & IV & $r \Lambda$ & $r \leqslant$ & $r \leqslant$ & rq & rq & $r \ldots \Lambda / r \ldots V$ \\
\hline $11 \mathrm{~V}$ & 171 & $V$ & $\Lambda$ & 10 & Ir & $r q$ & ro & IV & rq & ro & ro & rV & $\varepsilon$. & $r \ldots q / r \ldots \wedge$ \\
\hline$|r|$ & 170 & $V$ & $\Lambda$ & 17 & $1 \varepsilon$ & $r V$ & ry & 11 & $\varepsilon$ & ro & ro & $r \wedge$ & $\leqslant 1$ & $r \cdot 1 \cdot / r \ldots q$ \\
\hline Iro & IV. & $\wedge$ & 9 & 17 & $1 \leqslant$ & $r \wedge$ & $r v$ & 19 & \& & Yq & Yq & $r \wedge$ & $\varepsilon r$ & $r+11 / r+1$. \\
\hline $1 Y \Lambda$ & 187 & $\Lambda$ & 9 & IV & 10 & rq & $r \Lambda$ & 19 & $\varepsilon r$ & rV & rV & rq & \& & $r+\mid r / r+11$ \\
\hline ITY & 111 & $\Lambda$ & 9 & $1 V$ & 10 & $r$ & rq & $r$. & $\varepsilon r$ & Y^ & $r \wedge$ & $r$. & $\leqslant 0$ & $r \cdot I r / r \cdot I r$ \\
\hline $1 \% 4$ & 114 & 9 & 1. & 11 & 17 & $r$ & $\varepsilon$ & $r$ r. & $\leq \varepsilon$ & rq & rq & $r_{1}$ & $\varepsilon V$ & $r \cdot I \leqslant / r \cdot 1 r$ \\
\hline $1 \leqslant$. & $19 r$ & 9 & 1. & 11 & 17 & rr & \&1 & Y & $\leqslant 0$ & $r$. & $r$. & rr & $\varepsilon \wedge$ & $r+10 / r+1 \varepsilon$ \\
\hline $1 \leq 2$ & 191 & 9 & 11 & 19 & IV & $r r$ & $\varepsilon Y$ & YY & $\leqslant V$ & $m$ & $r$ & $r r$ & $\leqslant 9$ & $r .17 / r .10$ \\
\hline $1 \leqslant 9$ & $r \cdot r$ & 1. & 11 & $r$. & IV & $r \varepsilon$ & $\varepsilon r$ & $r r$ & $\leqslant \Lambda$ & Tr & $r r$ & $r \varepsilon$ & 0. & $r . I V / r+17$ \\
\hline
\end{tabular}

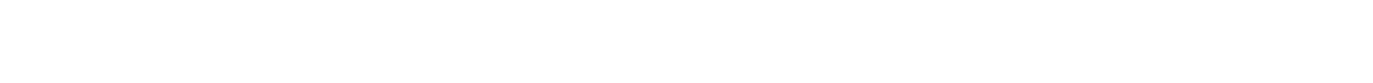

من الجطل السلق يتضح أن إجمالل عدطلاب التعليم البتدائي الرسمي لغلت عل مستوى

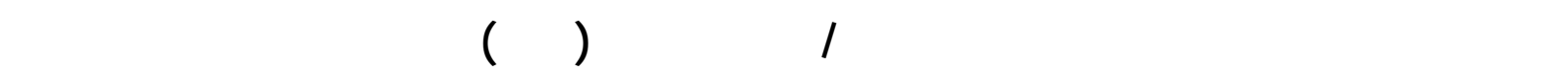

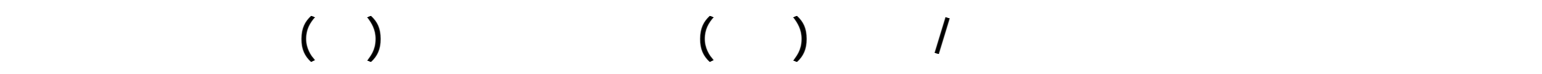

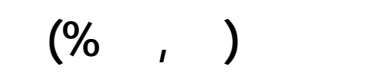

ج ـ - قَيرل أعدادطلاب التعليم الابدائ الخاص بمصروفت عل مستوى محاثلمشملسشيناء :

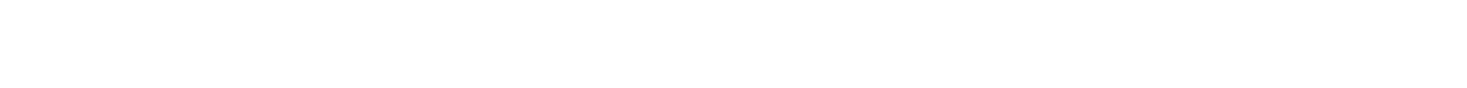

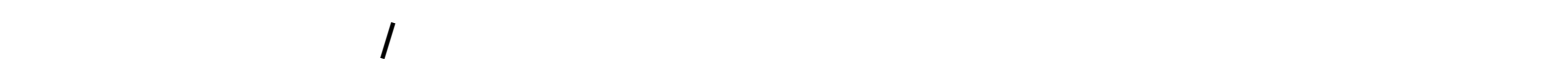

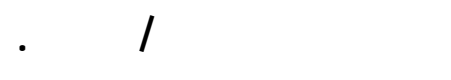


(Iع) ج (1)

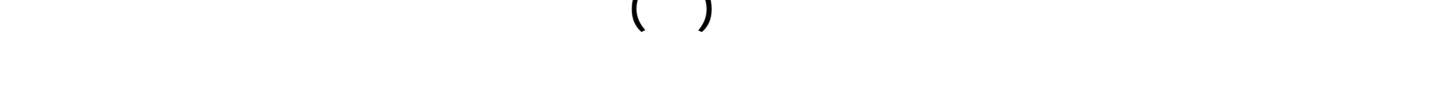

\begin{tabular}{|c|c|c|c|c|c|c|c|c|c|c|c|c|c|c|}
\hline \multicolumn{2}{|c|}{ الاجمالى } & \multicolumn{2}{|c|}{ السادس } & \multicolumn{2}{|c|}{ الخامس } & \multicolumn{2}{|c|}{ الرابع } & \multicolumn{2}{|c|}{ الثالث } & \multicolumn{2}{|c|}{ الثاني } & \multicolumn{2}{|c|}{ الأول } & \\
\hline 1 & $\dot{j}$ & 1 & $\dot{j}$ & 1 & $j$ & 1 & $\dot{j}$ & 1 & $\dot{j}$ & 1 & $\dot{j}$ & 1 & $\dot{j}$ & \\
\hline 718 & VYr & $\vee \wedge$ & 110 & Vo & $1 \cdot 1$ & 1.9 & Ir. & $1 \ldots$ & $1 \leqslant V$ & 119 & IrV & 147 & iro & $r \ldots \Lambda / r \ldots v$ \\
\hline $7+0$ & $\vee \wedge \bullet$ & $\Lambda$. & 111 & $V V$ & 111 & $11 \%$ & IrE & $1 \cdot r$ & 101 & Irr & $|r|$ & Irv & $1 \%$ & $r \ldots q / r \ldots \Lambda$ \\
\hline 700 & $\Lambda \cdot \Lambda$ & $\Lambda r$ & $|Y|$ & $\Lambda$ & 110 & 117 & 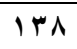 & 1.7 & 107 & $1 Y 4$ & $1 \% 0$ & $1 \leq 1$ & IrV & $r .1 \cdot / r . .9$ \\
\hline $7 V \varepsilon$ & Arr & $\Lambda \varepsilon$ & iro & $\Lambda r$ & 111 & 119 & $1 \leqslant r$ & 1.9 & 171 & $1 \%$ & 119 & $1 \leq 0$ & $1 \leq 1$ & $r .11 / r \cdot 1$. \\
\hline $79 \varepsilon$ & $\Lambda \bullet \Lambda$ & $\Lambda \vee$ & $14 q$ & $\Lambda \varepsilon$ & $|Y|$ & Irr & $1 \leq 7$ & $11 \%$ & 170 & $1 \% \varepsilon$ & $1 \leqslant r$ & 10. & $1 \leq 0$ & $r .1 r / r .11$ \\
\hline Vio & $\wedge \wedge \mu$ & 9. & Mr & $\Lambda V$ & iro & IrV & 101 & 117 & 18. & $1 \mathrm{H}$ & $1 \leq V$ & $10 \leq$ & 10 & $r \cdot|r / r \cdot| r$ \\
\hline VYV & 91. & $q r$ & IrV & 9. & $14 q$ & Ir. & 100 & 119 & 180 & $1 \leqslant r$ & lor & 109 & $10 \varepsilon$ & $r \cdot 1 \leqslant / r \cdot 1 r$ \\
\hline$v \circ 9$ & $q u V$ & 90 & $1 \leq 1$ & $q r$ & س & I & 17. & Irr & $1 \wedge 1$ & $1 \leq 7$ & 107 & 178 & 109 & $r .10 / r \cdot 1 \varepsilon$ \\
\hline VAY & 970 & 91 & $1 \leq 0$ & 90 & IrV & IrN & 170 & IrV & $1 \wedge 7$ & 101 & 171 & 171 & 178 & $r \cdot 1 T / r .10$ \\
\hline$\Lambda \cdot 0$ & $99 \leq$ & 1.1 & $1 \leqslant 9$ & 91 & $1 \leq 1$ & $1 \& Y$ & 18. & IT. & 194 & 100 & 177 & IVF & 171 & $r .1 V / r \cdot 17$ \\
\hline
\end{tabular}

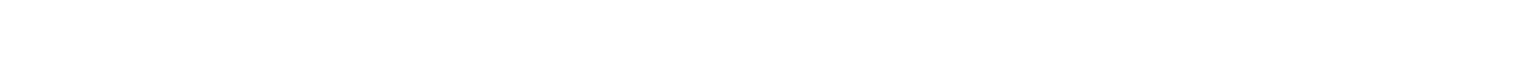

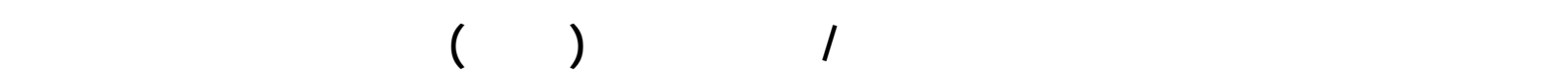

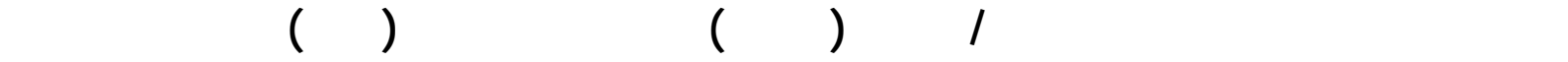

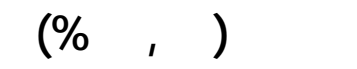

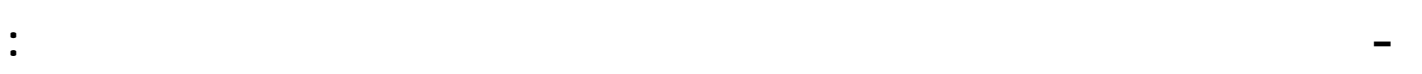

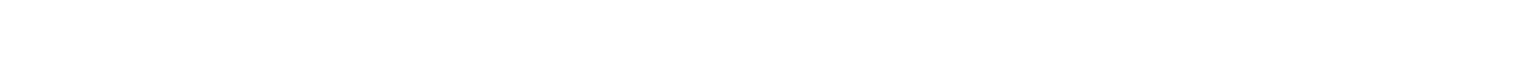

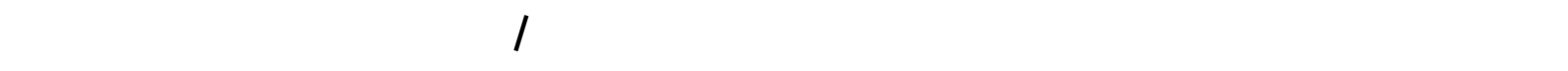

$$
. r \cdot 1 V / r \cdot 17
$$

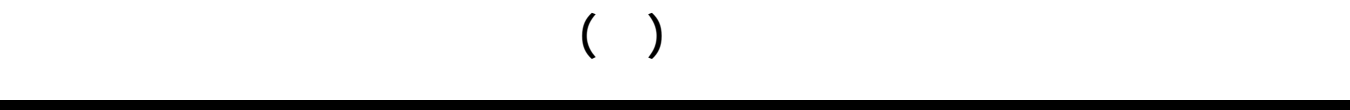

\begin{tabular}{|c|c|c|c|c|c|c|c|c|c|c|c|c|c|c|}
\hline \multicolumn{2}{|c|}{ الاجمالى } & \multicolumn{2}{|c|}{ السادس } & \multicolumn{2}{|c|}{ الخامس } & \multicolumn{2}{|c|}{ الرابع } & \multicolumn{2}{|c|}{ الثالث } & \multicolumn{2}{|c|}{ الثاني } & \multicolumn{2}{|c|}{ الأول } & إل \\
\hline 1 & $\dot{j}$ & 1 & j & 1 & j & 1 & $\dot{j}$ & 1 & $j$ & 1 & j & 1 & $\dot{j}$ & \\
\hline$V \leq$ & $9 \leq$ & $\mathrm{v}$ & $\Lambda$ & 1. & 11 & 10 & $\mathrm{v}$ & $\Lambda$ & 10 & $\Lambda$ & 11 & Y & $r_{0}$ & $r \ldots \wedge / r \ldots V$ \\
\hline VI & $9 V$ & $\mathrm{v}$ & $\Lambda$ & 1. & 11 & 10 & $\mathrm{v}$ & $\Lambda$ & 10 & $\Lambda$ & 11 & TV & $r 4$ & $r \ldots q / r \ldots \wedge$ \\
\hline$v \wedge$ & $1 \ldots$ & $v$ & 9 & 11 & IT & 17 & $\mathrm{v}$ & 9 & 17 & 9 & 19 & rA & $r v$ & $r \cdot 1 \cdot / r \ldots q$ \\
\hline$\Lambda 1$ & $1 . r$ & $\Lambda$ & 9 & 11 & IT & 19 & $\Lambda$ & 9 & 17 & 9 & $r$. & rA & $r_{\Lambda}$ & $r+11 / r+1$. \\
\hline$\Lambda r$ & 1.7 & $\Lambda$ & 9 & Ir & IT & IV & $\Lambda$ & 9 & IV & 9 & r. & rq & rq & $r+\mid r / r+11$ \\
\hline AT & 1.9 & $\Lambda$ & 1. & Ir & Ir & IV & $\Lambda$ & 1. & IV & 1. & YI & $r$. & $\varepsilon$. & $r \cdot \mid r / r \cdot I r$ \\
\hline$\Lambda \wedge$ & 114 & 9 & 1. & Ir & ir & 11 & 9 & 1. & 11 & 1. & Tr & $r 1$ & \&1 & $r .1 \leqslant / r \cdot 1 r$ \\
\hline 91 & 117 & 9 & 11 & $1 \pi$ & $1 \leqslant$ & 11 & 9 & 11 & 11 & 11 & Tr & rY & $\varepsilon r$ & r.10/T.1 \\
\hline $9 \leq$ & 119 & 9 & 11 & ir & $1 \leqslant$ & 19 & 9 & 11 & 19 & 11 & rT & $r \mu$ & $\varepsilon r$ & $r+17 / r+10$ \\
\hline $9 \mathrm{~V}$ & TrT & 1. & Tr & $1 \leqslant$ & 10 & $r$. & 1. & Ir & $r$. & Tr & $r \varepsilon$ & $r \varepsilon$ & $\leqslant \xi$ & r.IV/T.1T \\
\hline
\end{tabular}




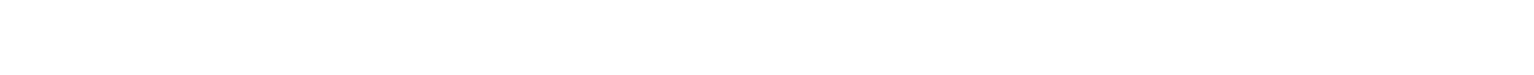

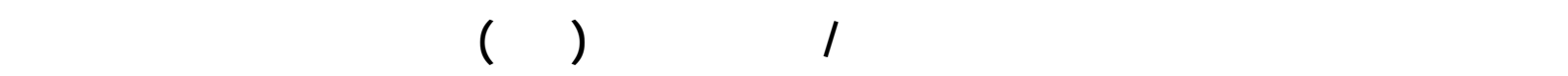

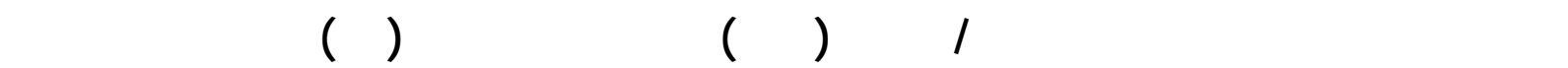
قرها ( וس\%\%).

المرحلة الثالثة:مرحلة التصور الفقترح للخربلة المربسية:

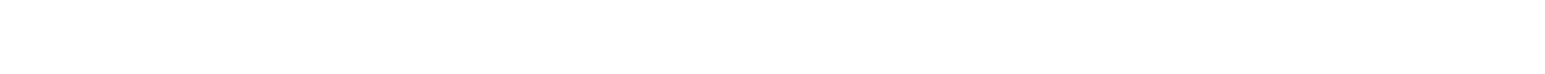
التالية :

ألولاً: مظالفل التصور الفقترح: I. المظلفلت الظاربة:

- تهل الخرطة المدرسية عل تعزبزمبدأ يموقرلاية النعليم ف مرحلته الأول وتهقي ق تك لهؤ

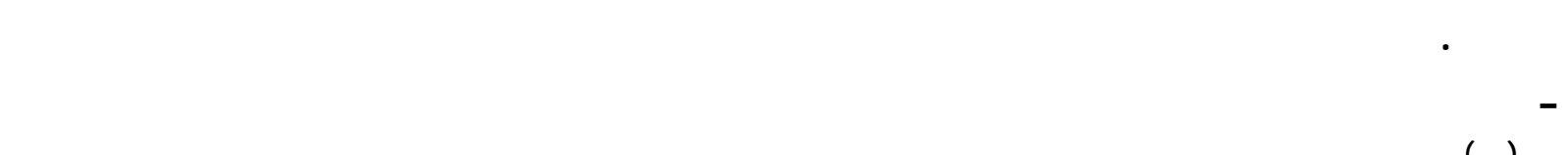
لها' (r.) - الخرطة المدرسية وسيلة فعالة لإحداث التنمية المحلية من كلفة جولنبها.

r. المظلفل الوفعية:

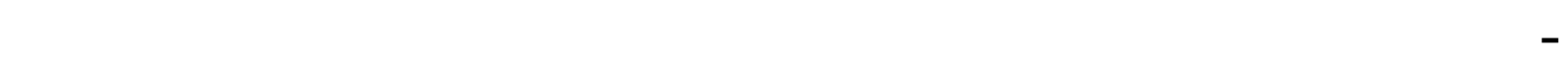

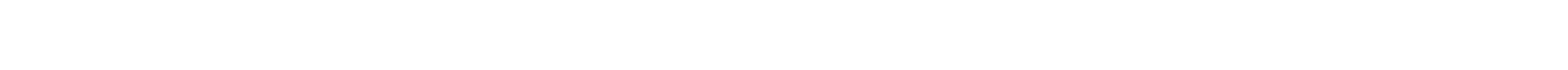

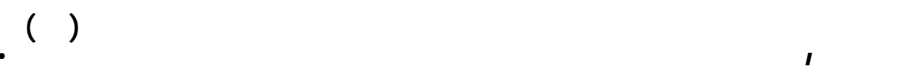

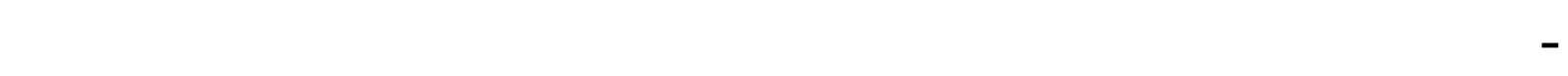

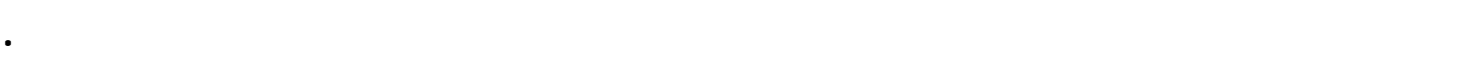
r. المظلقل التنبؤبة:

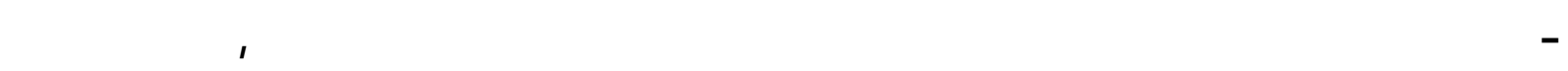

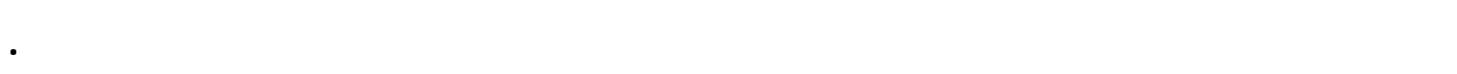
- الخربة المدرسية نملب علل تصميم بنائل مصور للمعلوملت الق تتوم شبكة المداوس

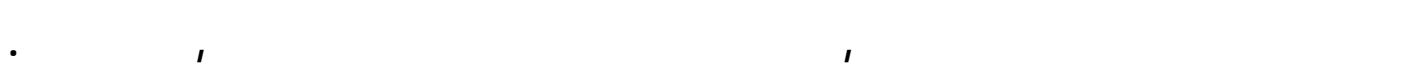


شانيا:متالبلت التصور الفقترح: يمالب بناء تصور الخرولة المدرسية الفترح تبف مجموعة من المعليير والمؤشرات والتي

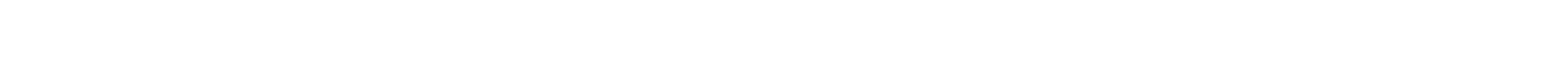

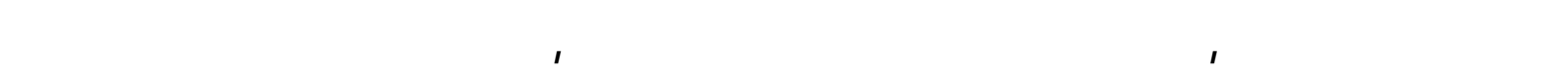
قل وزالرة التربية والنحليم, وضنه المؤشرلت هي: I ـ كثالفة الفطل الررلمي(معل تاميذلفطل): r. نصيب الفطل من المعالمبن(معلم لفطل):

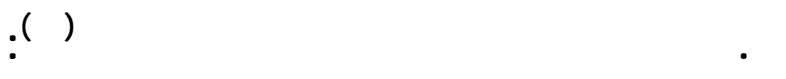

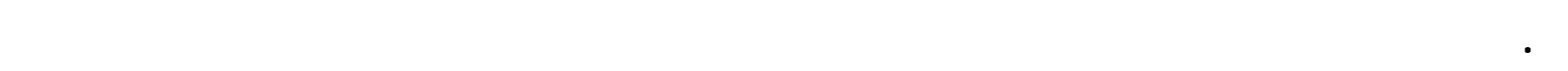
المسقبلية (rr')

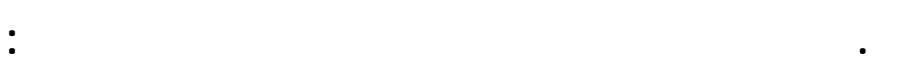

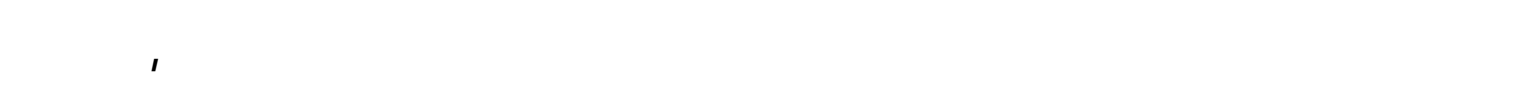

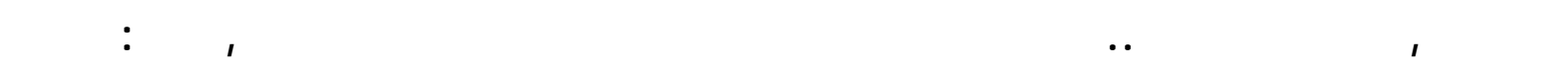
لـ 1 1 مسلب تكالف التجيدل الفترحة :

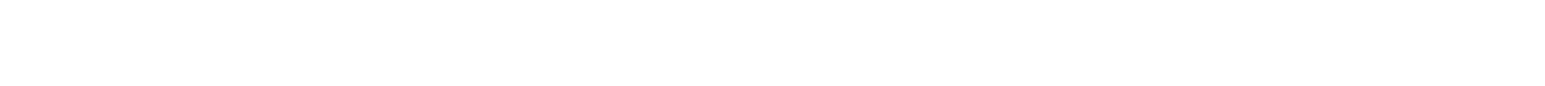

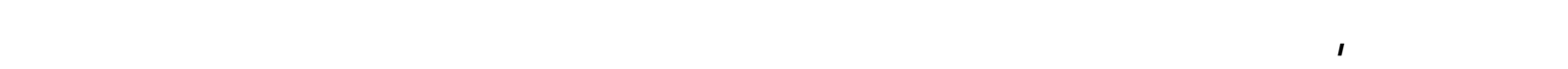
المتوقعة (ro)

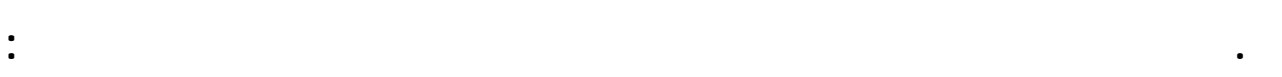

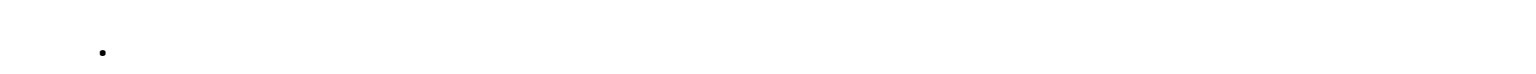

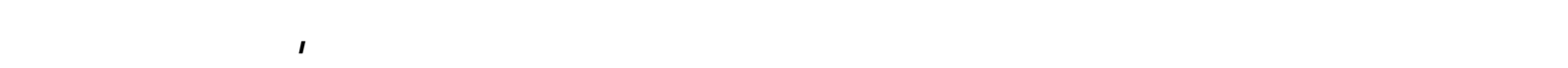

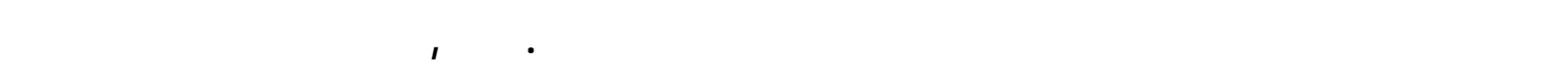

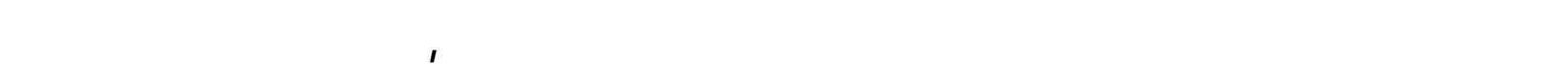
موفع المداوس أو أحجامها أو عسها (r7).

ثالثا : المعوقلت المتوقعة ألمل تففيذ التصور الفقترح:

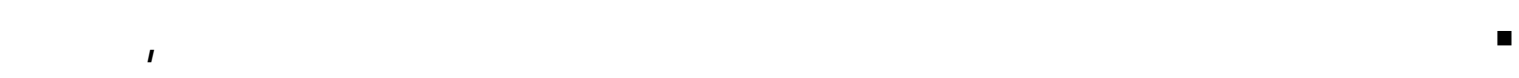
في الدط النامية. 


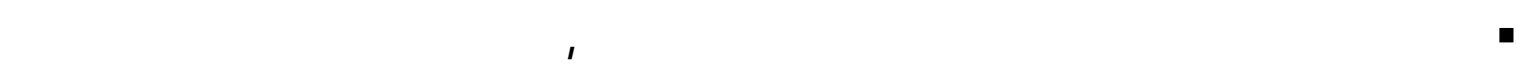

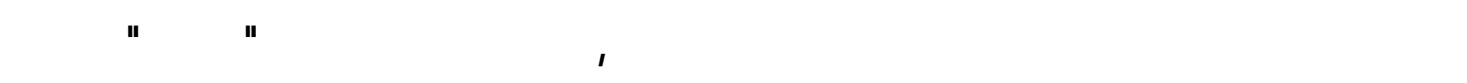
ورجة وعيهم بأهمية هنه الرملسلت.

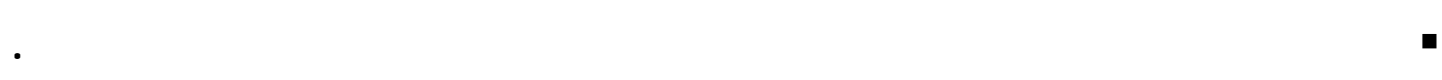
• عم وجود خرئل فهصيلية فيلسية اللبلدكل ولالمنلاق المختلفة بها.

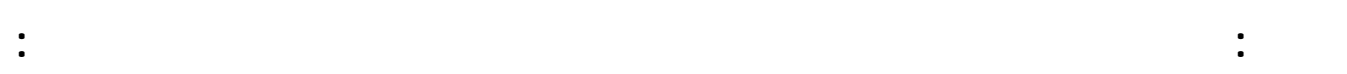

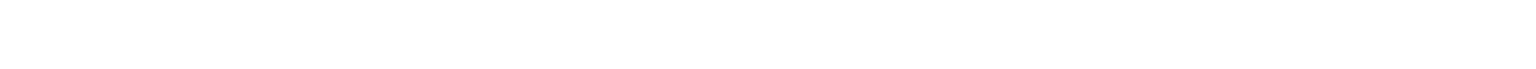

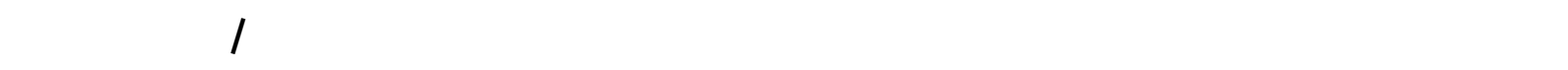

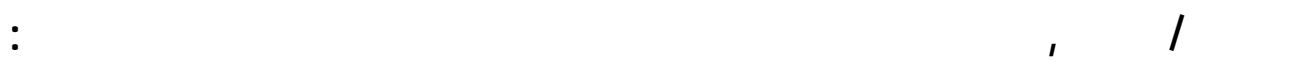

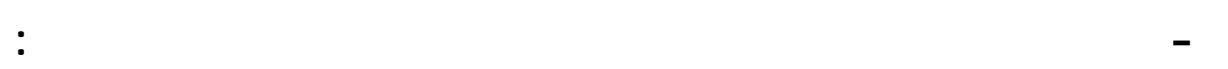

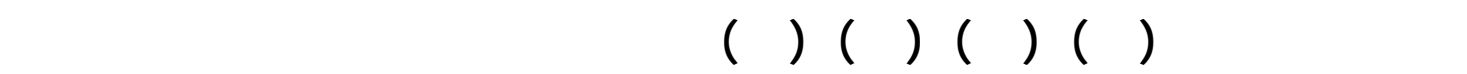

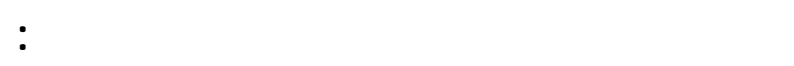

$$
\begin{aligned}
& \text { - }
\end{aligned}
$$

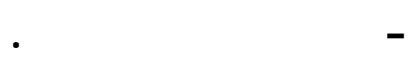

$$
\begin{aligned}
& \text { - تعلم خاص بمصروفلت. }
\end{aligned}
$$

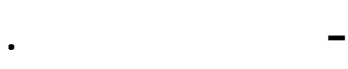

$$
\begin{aligned}
& \text { وفصبل ذلكفيما يل : }
\end{aligned}
$$

(17)

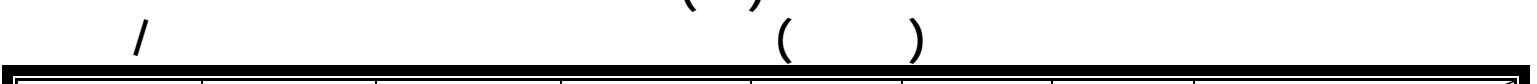

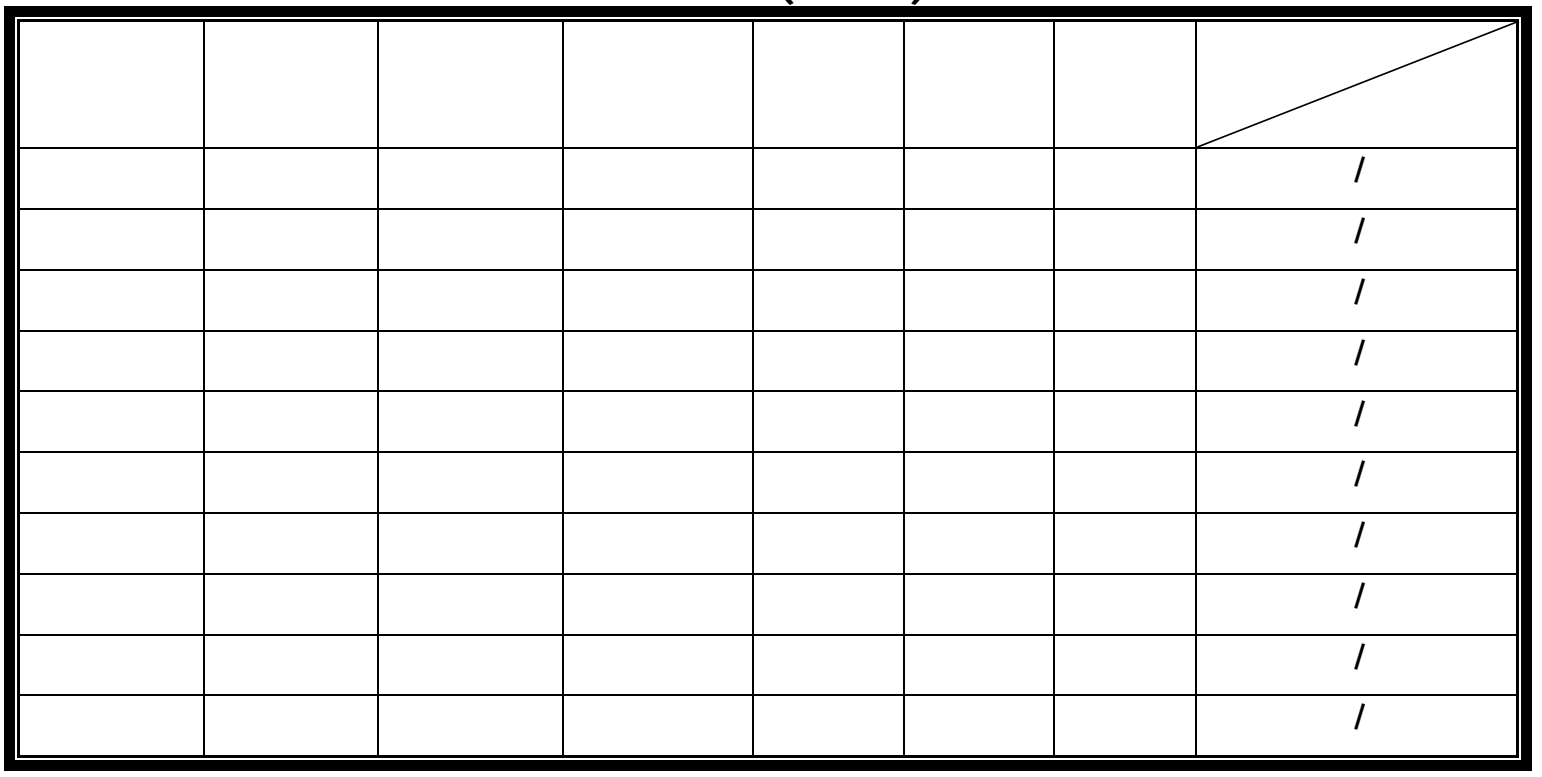




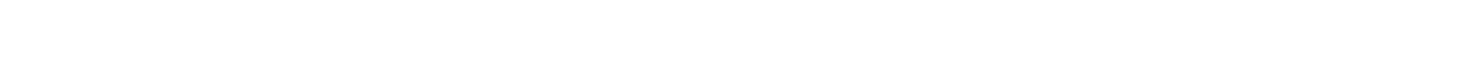

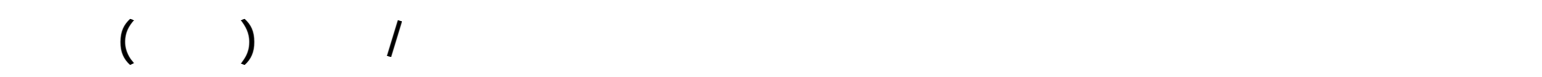

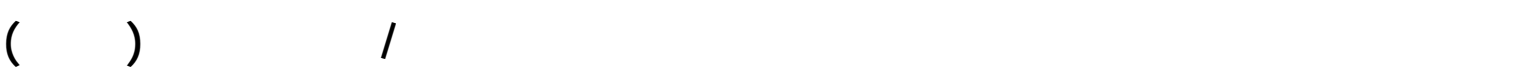

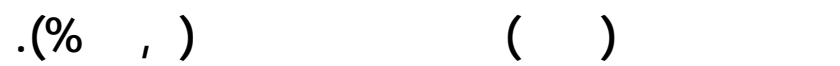

\section{(IV) ج}

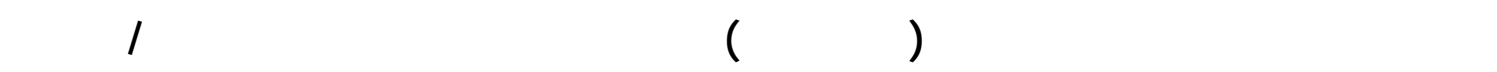

\begin{tabular}{|c|c|c|c|c|c|c|c|}
\hline الاجمالى & السـادس & الخامس & الرابع & الثالث & الثاني & الأول & \\
\hline $1 \varepsilon$ & 1 & 1 & $r$ & $r$ & $r$ & $r$ & $r \ldots \Lambda / r \ldots v$ \\
\hline $1 \leqslant$ & 1 & 1 & $r$ & $r$ & $r$ & $r$ & $r \ldots q / r \ldots \Lambda$ \\
\hline 10 & 1 & 1 & $r$ & $r$ & $r$ & $r$ & $r \cdot 1 \cdot / r \ldots q$ \\
\hline 10 & 1 & 1 & $r$ & $r$ & $r$ & $r$ & $r .11 / Y .1$. \\
\hline 17 & 1 & 1 & $r$ & $r$ & $r$ & $r$ & $r+\mid r / r \cdot 11$ \\
\hline 17 & 1 & 1 & $r$ & $r$ & $r$ & $r$ & $r+I r / r+1 r$ \\
\hline IV & 1 & 1 & $\varepsilon$ & $r$ & $\varepsilon$ & $\varepsilon$ & $r \cdot 1 \leq / r \cdot 1 r$ \\
\hline IV & 1 & 1 & $\varepsilon$ & $\varepsilon$ & $\varepsilon$ & $\varepsilon$ & $r+10 / r \cdot 1 \leqslant$ \\
\hline 11 & 1 & 1 & $\varepsilon$ & $\varepsilon$ & $\varepsilon$ & $\varepsilon$ & $r+1 T / r+10$ \\
\hline 11 & 1 & 1 & $\varepsilon$ & $\varepsilon$ & $\varepsilon$ & $\varepsilon$ & $r .1 V / Y .17$ \\
\hline
\end{tabular}

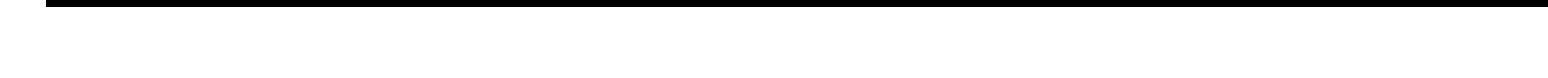

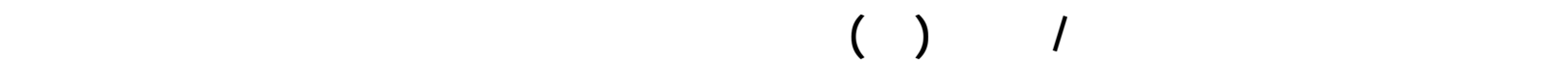

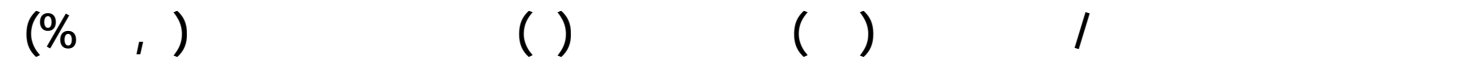

\section{(11) a}

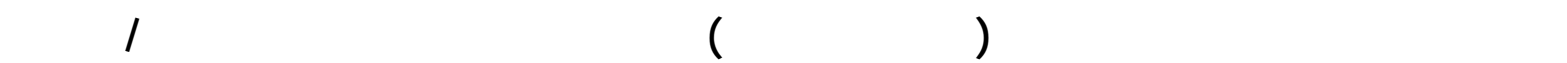

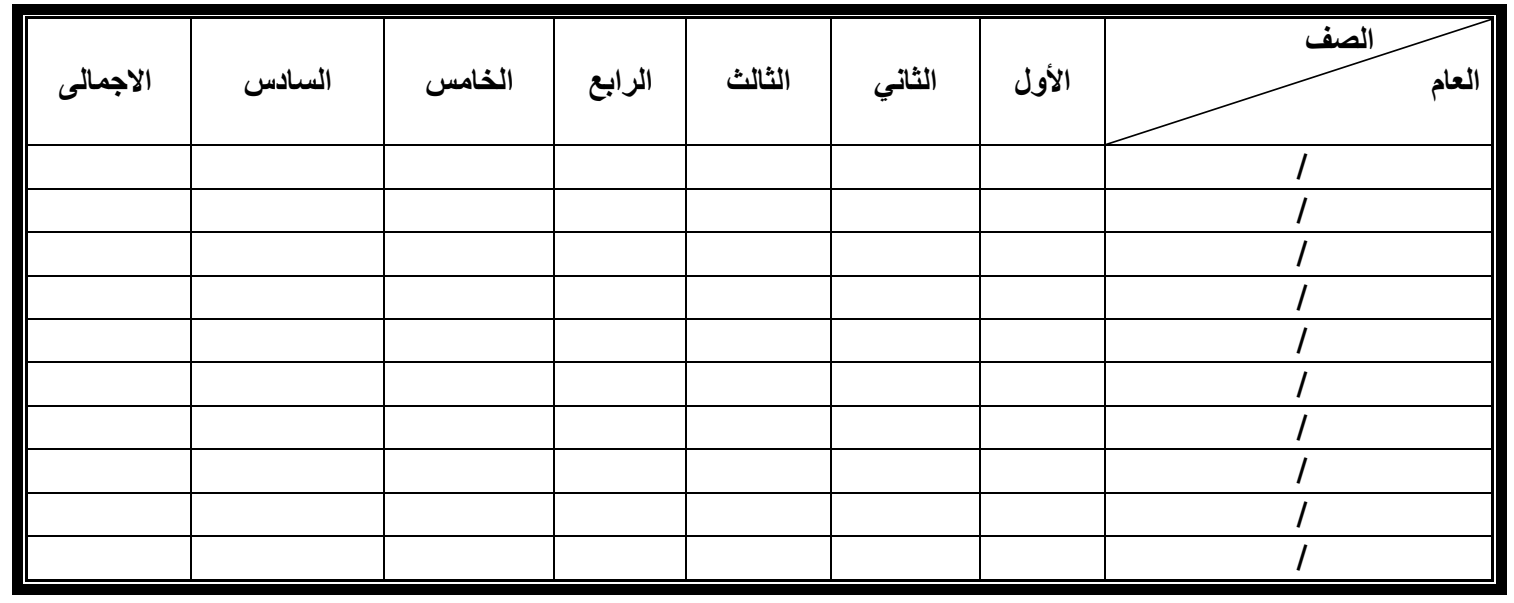




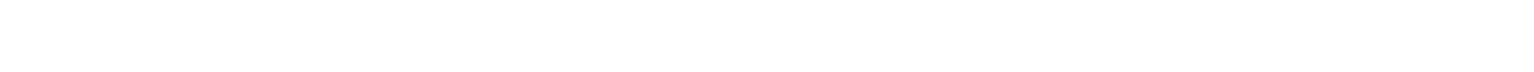

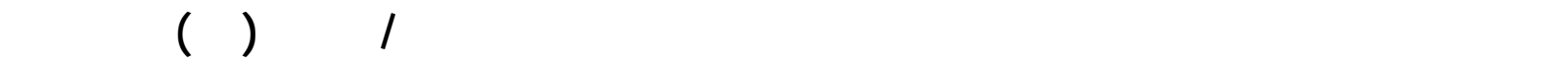

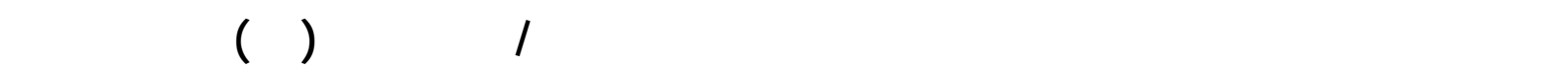
-

\section{(19) ج (19)}

قديرك أعدادفصط النعليم الابتدائ (خله النالت ) بمحالفلقشمل

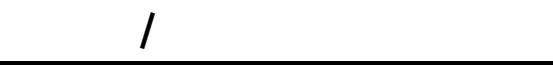

\begin{tabular}{|c|c|c|c|c|c|c|c|}
\hline اللجمال & الساس & الخلس & الرليع & الثالث & النالي & الأط & الصف \\
\hline Ir & $\boldsymbol{r}$ & $\boldsymbol{r}$ & $\boldsymbol{r}$ & $\boldsymbol{r}$ & $\boldsymbol{r}$ & $\mu$ & 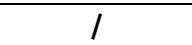 \\
\hline Ir & $\boldsymbol{r}$ & $\boldsymbol{r}$ & $\boldsymbol{r}$ & $\boldsymbol{r}$ & $r$ & $\mu$ & ץ.:৭/ץ./A \\
\hline $1 \varepsilon$ & $\boldsymbol{r}$ & $\boldsymbol{r}$ & $\boldsymbol{r}$ & $\boldsymbol{r}$ & $r$ & $\boldsymbol{\mu}$ & r.l./r..q \\
\hline $1 \varepsilon$ & $\mathbf{r}$ & $\boldsymbol{r}$ & $\mathbf{r}$ & $\mathbf{r}$ & $r$ & $\boldsymbol{\mu}$ & r. II/r. I. \\
\hline 10 & $\mathbf{r}$ & $\boldsymbol{r}$ & $\boldsymbol{r}$ & $\boldsymbol{r}$ & $r$ & $\boldsymbol{\mu}$ & r. \\
\hline 10 & $\boldsymbol{r}$ & $r$ & $\boldsymbol{r}$ & $\boldsymbol{r}$ & $r$ & $\boldsymbol{\mu}$ & r.r/א. \\
\hline 10 & $\boldsymbol{r}$ & $\boldsymbol{r}$ & $\boldsymbol{r}$ & $\boldsymbol{r}$ & $r$ & $\boldsymbol{\mu}$ & $r \cdot|\varepsilon / r \cdot| r$ \\
\hline 17 & $\boldsymbol{r}$ & $\boldsymbol{r}$ & $\boldsymbol{r}$ & $\boldsymbol{r}$ & $r$ & $\varepsilon$ & $r \cdot 10 / r \cdot 1 \varepsilon$ \\
\hline 17 & $\boldsymbol{\mu}$ & $\boldsymbol{\mu}$ & $r$ & $r$ & $r$ & $\boldsymbol{\varepsilon}$ & $r \cdot 17 / r \cdot 10$ \\
\hline IV & $\boldsymbol{\mu}$ & $\boldsymbol{\mu}$ & $\boldsymbol{\mu}$ & $\boldsymbol{\mu}$ & $\boldsymbol{\mu}$ & $\varepsilon$ & r. IV/r. IT \\
\hline
\end{tabular}

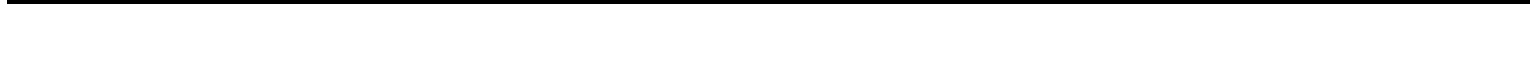

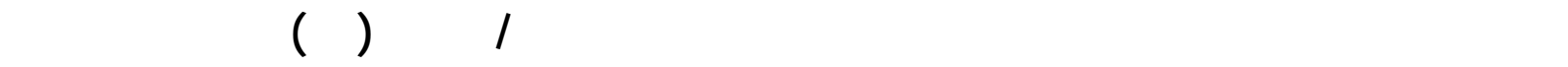

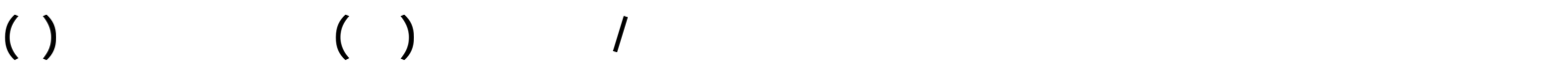

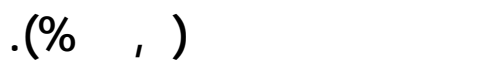

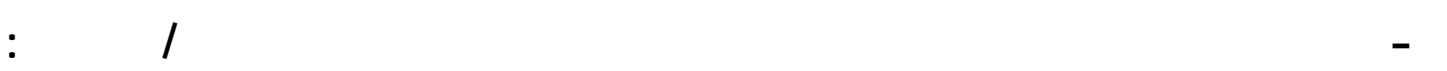

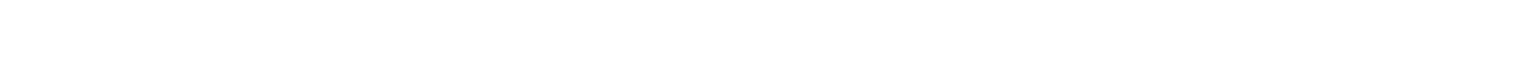

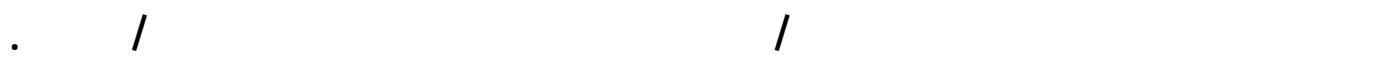
(r.) ج (r)

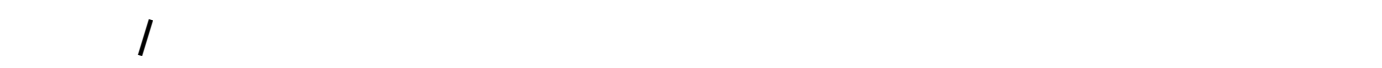

\begin{tabular}{|c|c|c|c|c|c|c|c|c|c|c|}
\hline $\begin{array}{l}r \cdot 17 \\
r \cdot 1 V\end{array}$ & $\begin{array}{l}r .10 \\
r .17\end{array}$ & $\begin{array}{l}r \cdot 1 \varepsilon \\
r \cdot I^{\prime}\end{array}$ & $\begin{array}{l}r \cdot I r \\
r \cdot I \varepsilon\end{array}$ & $\begin{array}{l}r \cdot I r \\
r \cdot I r\end{array}$ & $\begin{array}{l}r \cdot I I \\
r . \mid r\end{array}$ & $\begin{array}{l}r \cdot 1 . \\
r .11\end{array}$ & $\begin{array}{c}1 \% . .9 \\
r .1 .\end{array}$ & $\begin{array}{l}r \cdot . \wedge \\
r \cdot . q\end{array}$ & $\begin{array}{l}r \cdot r v \\
r \cdot . \wedge\end{array}$ & المادة \\
\hline 10.5 & $1 \leqslant 01$ & $1 \leq 17$ & IFV. & |r|r| & IYYY & IYYE & IYIT & $11 V V$ & $11 Y V$ & فصل فدس \\
\hline $7 r \varepsilon$ & 717 & $7 \ldots$ & $O \wedge Y$ & 077 & 001 & OH & 019 & 0.1 & $\varepsilon \wedge r$ & لغة عربية \\
\hline$r V T$ & $r q r$ & YOS & $r \leqslant V$ & $r \varepsilon$. & rrr & YYY & 119 & YIT & $r \cdot \Lambda$ & إنجليزية لغة \\
\hline YOs & $r \leqslant V$ & $r \varepsilon$. & Yr & Yro & 119 & YIr & $r \cdot V$ & $r \ldots$ & 194 & رياضيات \\
\hline 149 & IY & Tr & 111 & 110 & 111 & 1.7 & $1 \cdot \varepsilon$ & $1 \ldots$ & $9 V$ & علوم \\
\hline 19 & $\Lambda Y$ & $\Lambda$. & $V V$ & VY & $V \varepsilon$ & VI & 71 & 71 & $7 \varepsilon$ & در اسات \\
\hline$r \wedge \wedge$. & rV^q & YVIr & rqYo & roor & $r \leqslant 0$. & rrVr & rrr. & r roq & YIVI & لى \\
\hline
\end{tabular}


من خلال الجطل السلق النى تنالط قفيرل أعدادمعلى التعليم الابتدائ عل مستوى محانلة

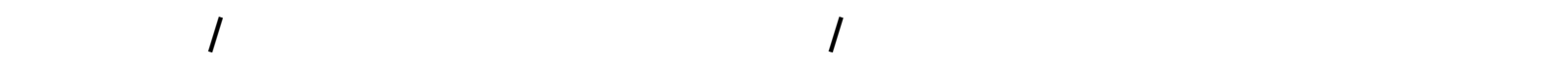
: ملاطة ما ئأقى

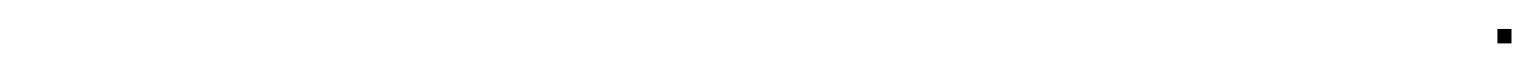

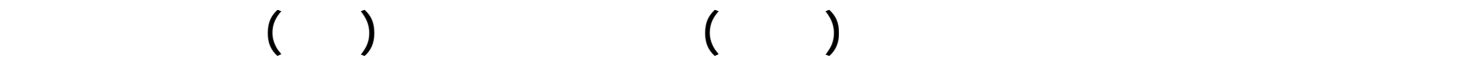

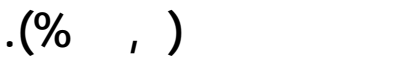

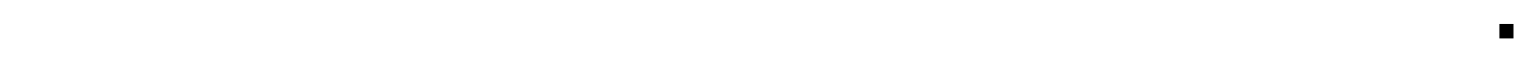

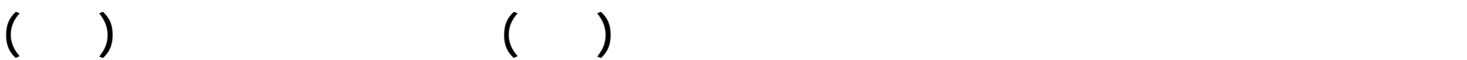
معاما بنسبة زبالةقردها (1,0

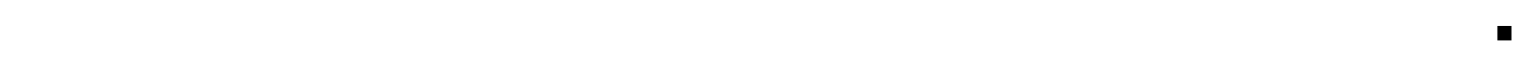

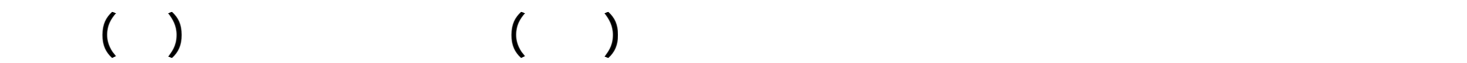

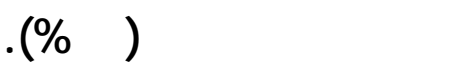

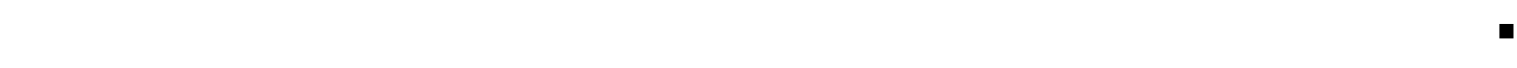

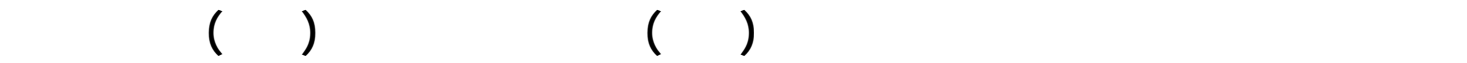

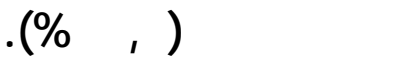

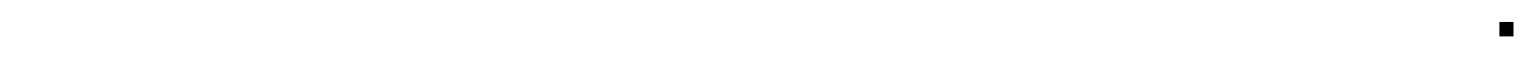

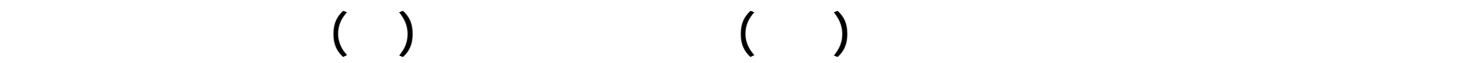
قرها (مسو\%).

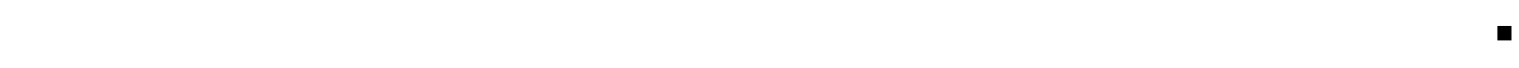

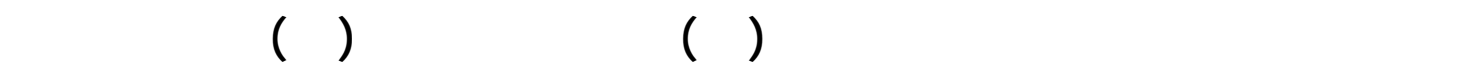

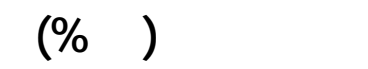

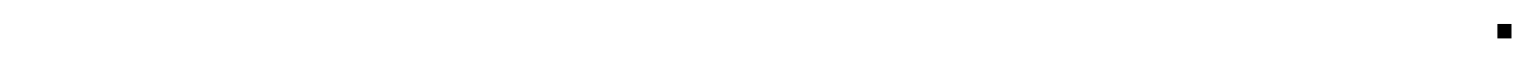

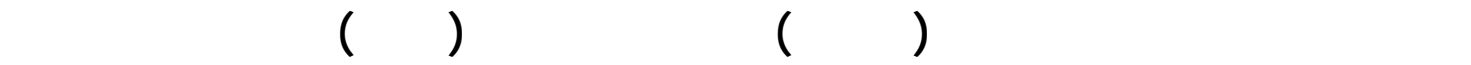

قرها (10, (\%)

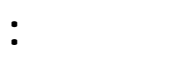

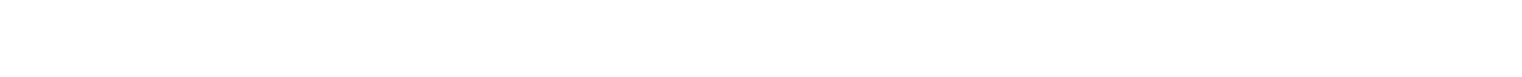

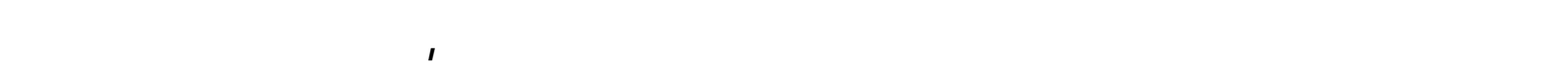

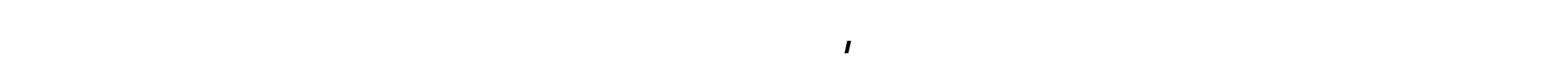

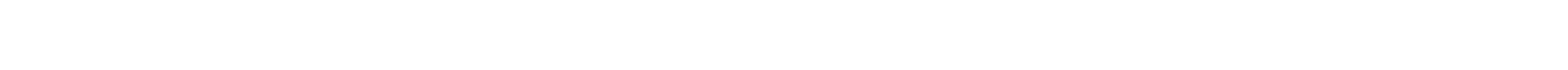
مؤشرات نموفي المسقل فئل 
التوصيلت والقفترحك :

في ضوء الدرلسة ونتائجها يمكن قِيم التوصيلت والفقترحك الآتية:

ألولا : التوصيلت :

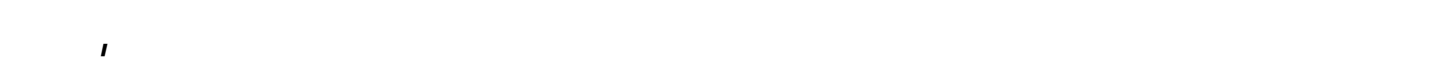
ينتلبب والعدد الإجمالي التلاميذخلالسسنولت الخرولة المترقةة.

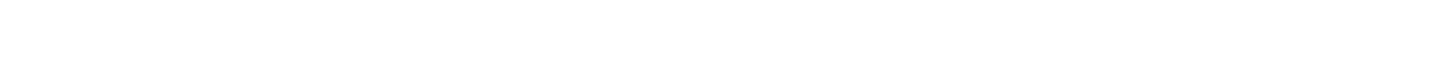
المستمرةفي عدد التلاميذفيلى علم. - مرونة المبف المدري وتزوبه بالخملت اللازمة.

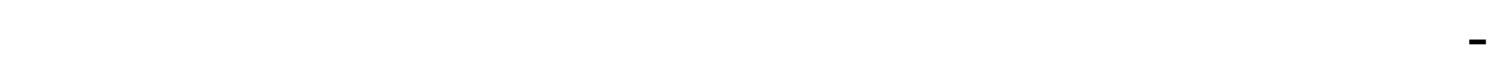
لا تؤثرفي أذاء المملية التهليمية.

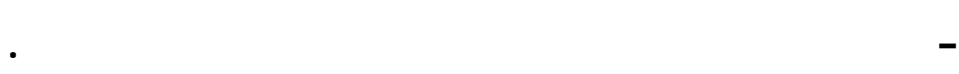

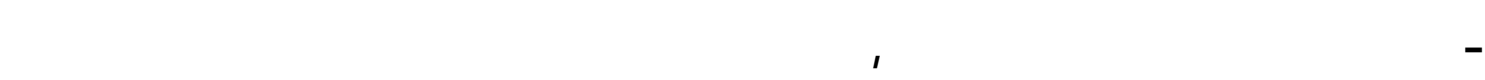

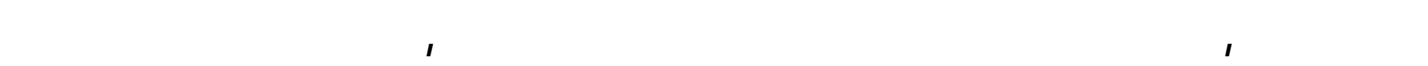
المنذفضةروالمنتشرةكثيراف المحلغلة. شانيا : الهقترحك:

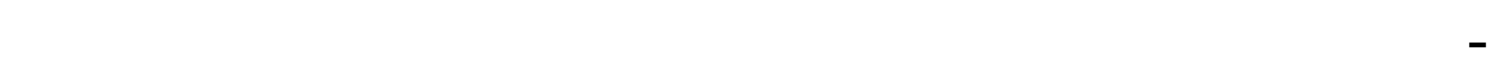
ظروفها السائة. - وضع خرولة مدرسية اللتعليم الفف بمحانغلقشملسسيناء. - وضع خربلة مدرسية اللتعليم الثلنوى بمحلغلمشملسبسيناء. - وضع خربلة مدرسية اللتمليم الفف بمحلغلقشملسشيناء. 


\section{المراجع}

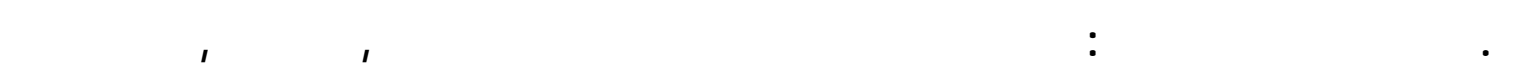

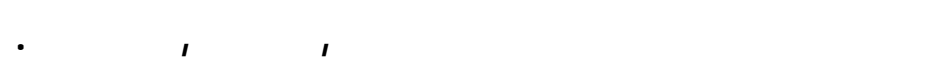

2. Galabawa , J. Agu , A .Ichiro , M." The impact of school mapping in the development of education in Tanzania" : As assessment of the experiences of Districts . Evaluation and program planning, vol . 25 , no . 2 ,2002. pp . $23-33$

3. Galabawa , J. Agu , A .Ichiro, M. Ibid, pp . 23 - 33.

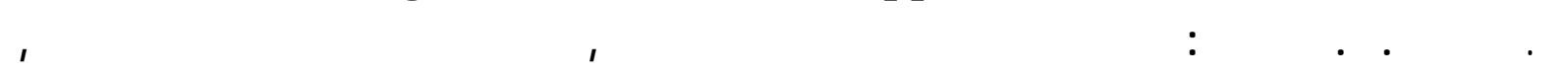

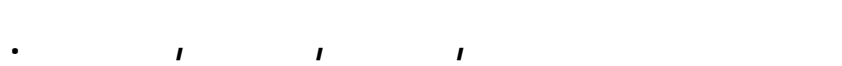

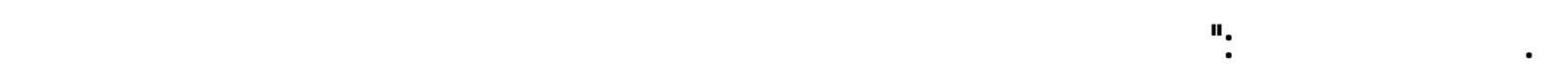

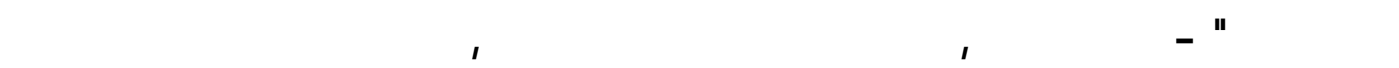
التربوبة, جامعة الفلهرة, 1997.

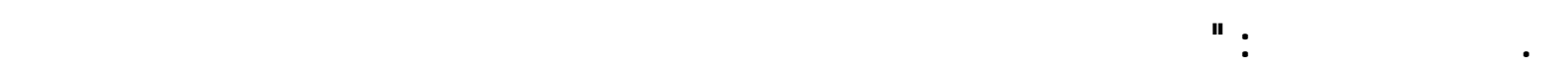

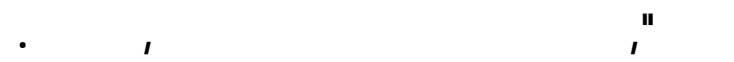

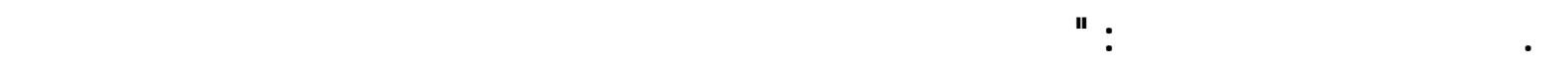

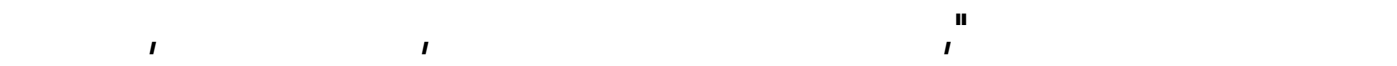
المنصورة,r r. r. r.

8. . Galabawa , J. Agu , A .Ichiro, M. Ibid, pp . 23 - 33

9. pizzolato,d.. Broseghini, F.\& Lorena: "School location mythology in urban areas of developing countries". International Transaction in Operational Research,. vol. 11,No.6, 2004, publisher; Blackwell publishing. - 1 ـ محمسيف البن فهم: التظليا التعليم ألسسه وأساليبه ومشكلانه, مكنبة الأنجلو المصرية,

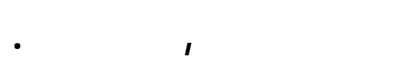

I I ا المرجع السلق.

12. Mendelson J.M., Education Planning and management and The use of geographical information system, UNESCO Publishing IIEP: Paris.pp8,9.

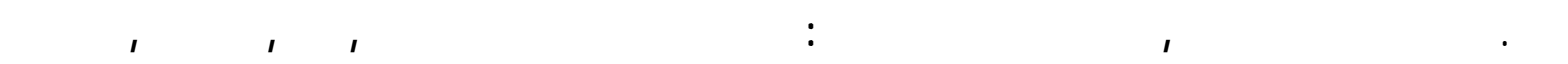

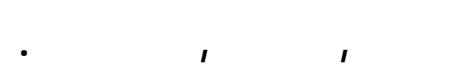

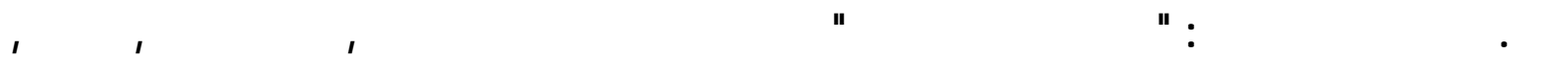

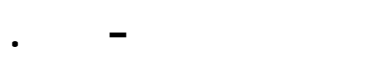

15. Galabawa, J. Agu, A .Ichiro, M. Ibid, pp . 23 - 33.

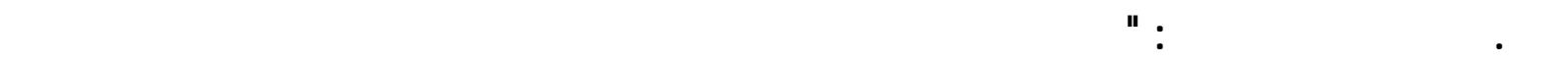

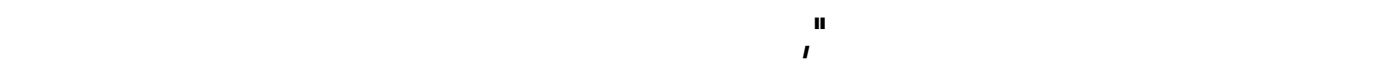




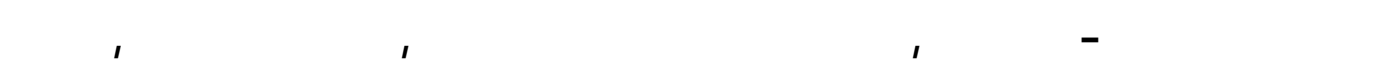

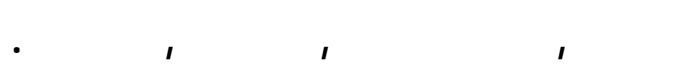

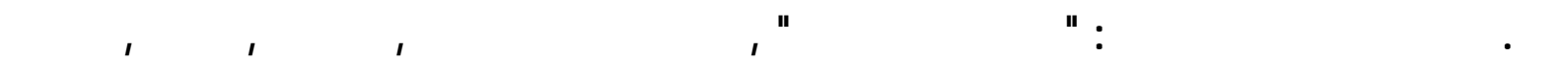
.07 • ص 1974

18. Unesco : Micro- Level Educational planning and Management ,Unesco principle Regional Office for Asia and The Pacific, Bangkok, 1991,.,pp.69,72.

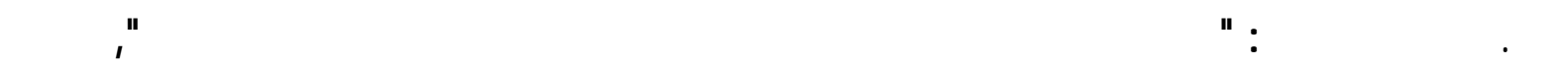

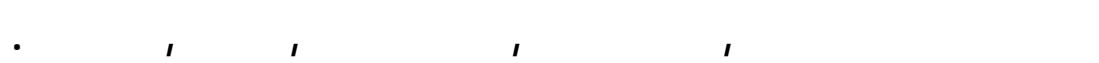

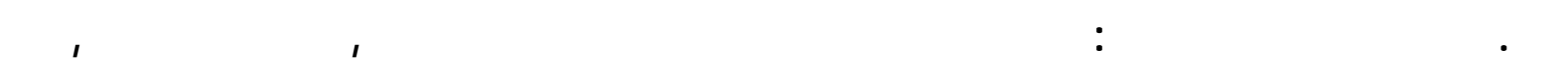
$.1 \mathrm{VV}$

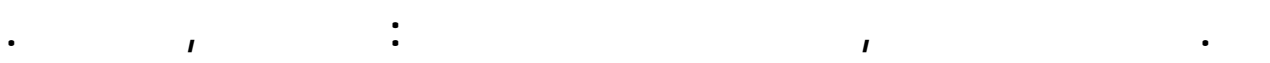

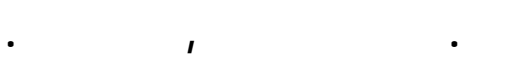

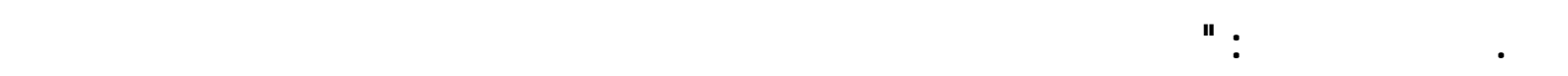

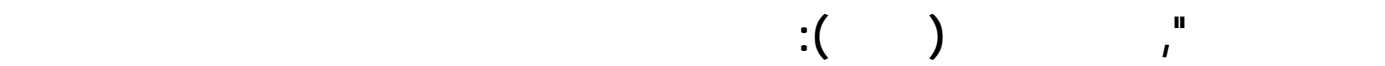

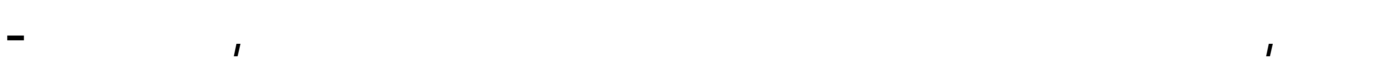

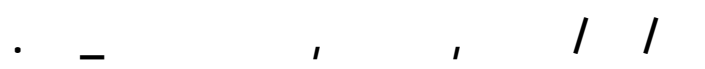

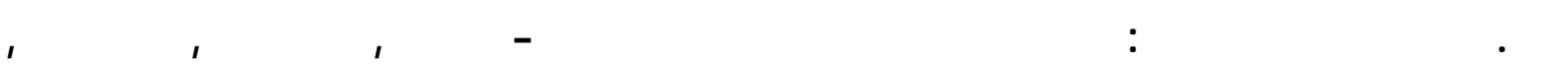

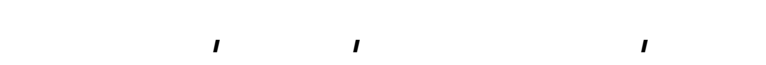

ro. المرجع السلق, ص • ^r.

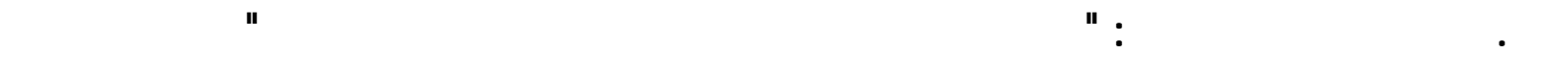

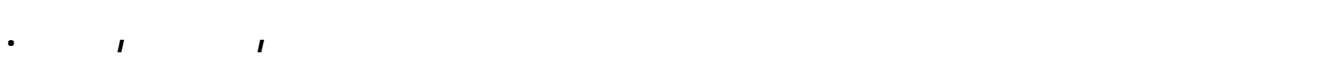

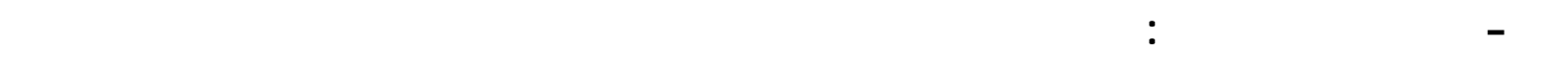

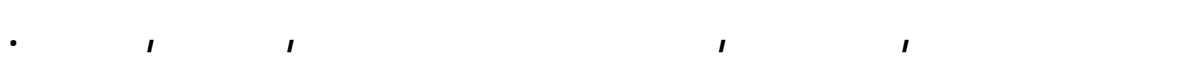

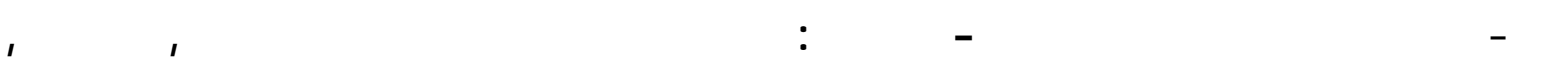

$$
\text { • • • (1917 }
$$

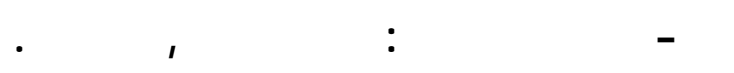

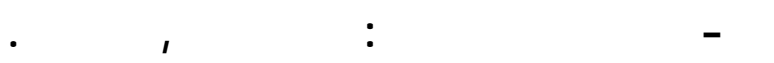

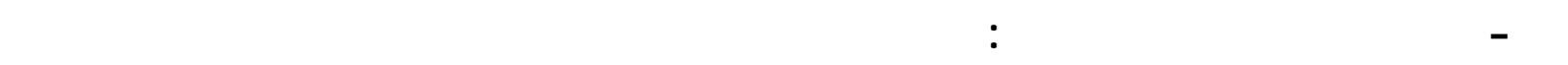

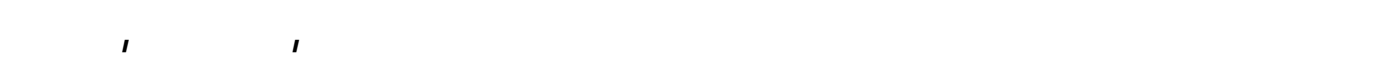

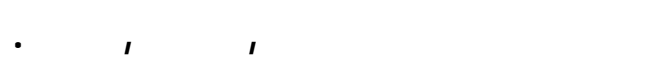

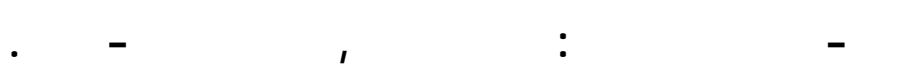

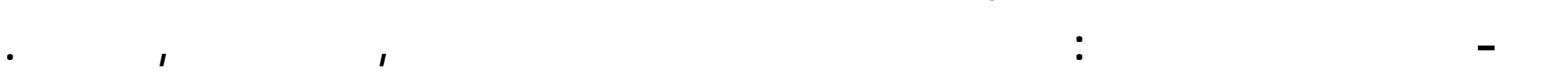

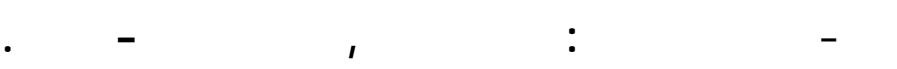

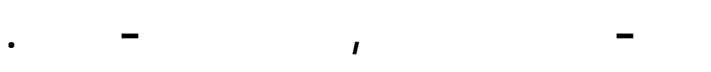

